\title{
Revisión bibliográfica de Implantología Bucofacial del año 2007
}

\author{
Bibliographical review of Oral Implantology of the year 2007
}

\author{
SÁNCHEZ GARCÉS MA* \\ PÉREZ ÁLVAREZ D** \\ MAYOR SUBIRANA G** \\ ALVES PEREIRA, D** \\ SANCHO PUCHADES IM** \\ GRAU MANCLÚS V** \\ PÁRRAGA LINARES L** \\ RODRÍGUEZ ARGUETA O*** \\ ABAD GALLEGOS $\mathbf{M} * * *$ \\ VARGAS ESPINOSA ML*** \\ MASIP ZURRIAGA E*** \\ ROURE VIÑ̃ALS N*** \\ FORTES MENESES $\mathbf{A} * * * *$ \\ EL-NAR M M**** \\ GAY ESCODA C $* * * * *$
}

Sánchez Garcés MA, Pérez Álvarez D, Mayor Subirana G, Alves Pereira, D, Sancho Puchades M, Grau Manclús V, Párraga Linares L, Rodríguez Argueta O, Abad Gallegos M, Vargas Espinosa ML, Masip Zurriaga E, Roure Viñals N, Fortes Meneses A, El-Nar M, Gay Escoda C. Revisión bibliográfica de Implantología Bucofacial del año 2007. Av Periodon Implantol. 2009; 21, 2: 89-116.

\section{RESUIMEN}

Se expone una revisión de la literatura científica publicada en revistas indexadas durante el año 2007 sobre Implantología Bucofacial. La escasez de tiempo de que disponen los profesionales para consultar las múltiples fuentes de información, ha motivado a los autores a resumir los artículos publicados y clasificarlos en los siguientes apartados: generalidades, pacientes especiales, superficies y diseños, tejidos blandos, implantes inmediatos, carga inmediata, complicaciones, elevación sinusal, técnicas avanzadas, plasma rico en plaquetas y factores de crecimiento, cirugía guiada, cirugía mínimamente invasiva y miniimplantes, con la intención de facilitar una puesta al día.

PALABRAS CLAVE: Implantología bucal, plan de tratamiento, pacientes especiales, diseño y superficies, tejidos blandos, implantes inmediatos, carga inmediata, complicaciones, elevación sinusal, técnicas avanzadas, plasma rico en plaquetas y factores de crecimiento, cirugía guiada, cirugía mínimamente invasiva y miniimplantes.

* Doctora en Medicina. Estomatóloga. Máster en Cirugía e Implantología Bucal. Profesora asociada de Cirugía Bucal y Profesora del Máster de Cirugía Bucal e Implantología Bucofacial. Facultad de Odontología de la Universidad de Barcelona. Investigadora del Instituto UB-IDIBELL.

** Licenciado en Odontología. Residente del Máster de Cirugía Bucal e Implantología Bucofacial. Facultad de Odontología de la Universidad de Barcelona.

*** Licenciado en Odontología. Diploma de Postgrado de Cirugía Dento-alveolar/Implantología Bucofacial. Facultad de Odontología de la Universidad de Barcelona.

**** Licenciado en Odontología. Diploma de Postgrado de Implantología Bucofacial. Facultad de Odontología de la Universidad de Barcelona.

***** Doctor en Medicina. Estomatólogo. Especialista en Cirugía Maxilofacial. Catedrático de Patología Quirúrgica Bucal y Maxilofacial. Director del Máster de Cirugía Bucal e Implantología Bucofacial. Facultad de Odontología de la Universidad de Barcelona. Investigador coordinador del Instituto UB-IDIBELL. Jefe del Servicio de Cirugía Bucal, Implantología Bucofacial y Cirugía Maxilofacial del Centro Médico Teknon. Barcelona. 


\section{SUMMMARY}

The lack of the available time of the professionals involved in the Odontological field and the difficulty to maintain a good level of information about Oral Implantology, arouse the interest of the authors to expose a synthetic review of the publications. Inside this article there are different aspects related to treatment planning, special patients, design and surfaces, immediate load, PRP, guided surgery and others.

KEY WORDS: Oral Implantology, treatment planning, special patients, implant surface, immediate load, complications, sinus lift, PRP, grow factors, guided surgery, miniimplants.

Fecha de recepción: 16 de septiembre de 2008.

Fecha de aceptación: 2 de octubre 2008.

\section{GENERALIDADES}

Actualmente existe una tendencia clara a analizar la literatura científica de forma sistemática, con el fin obtener la máxima evidencia que permita dar respuesta a las dudas que surgen en la praxis diaria de la Implantología bucofacial. El resultado de estas revisiones a menudo es pobre, aclarando pocas incógnitas, debido al rigor con que se establecen los criterios de selección de los artículos y las normas del análisis de los resultados. Los estudios disponibles son poco homogéneos ya sea debido a la muestra, el seguimiento o los resultados recogidos, y en consecuencia las conclusiones no son estadísticamente significativas por la escasez del material analizado. A pesar de estas consideraciones, somos absolutamente partidarios de este tipo de fuentes de información secundarias y terciarias (revisiones sistemáticas y metaanálisis).

Se ha publicado durante el año 2007, un suplemento de la revista oficial de la Academia Americana de Oseointegración que recomendamos y que es de obligada lectura para los profesionales interesados en la Implantología (1). En su introducción se especifican las normas de selección y de recogida de datos de los artículos revisados. La finalidad de la publicación fue encontrar respuestas a las siguientes preguntas: ¿Cómo afecta el tiempo de carga de una prótesis fija o removible en el resultado final de los implantes?, ¿Qué técnica de regeneración ósea da mejor soporte para la colocación de los implantes?; en los pacientes que requieren una restauración unitaria: ¿Cuáles son los resultados de los implantes en comparación con las restauraciones sobre dientes endodonciados?, ¿Afecta el tipo de prótesis a los resultados en la res- tauración de una arcada completa?, ¿Afecta el tipo de prótesis en los casos de edentulismo parcial?, ¿Cómo afectan el tabaco, la diabetes y la periodontitis al resultado final de las rehabilitaciones con implantes?, y por último, ¿Cómo afecta, al resultado final, el tiempo de colocación de los implantes después de una exodoncia? $(1,2)$. Este trabajo es realmente prometedor, ya que incluye todas las preguntas sobre las cuales quisiéramos tener una respuesta, aunque esperamos que no les decepcionen mucho. En esta misma línea se encuentra también un metaanálisis que pretende analizar el estado actual de la Implantología (2).

A parte de las preguntas anteriormente formuladas, hay muchas otras que quisiéramos que también tuvieran una respuesta ya que suscitan un interesante debate entre los profesionales, como son: La anestesia, la administración de antibióticos o qué método radiológico usar para el estudio de un caso de rehabilitación bucal con implantes.

Una correcta técnica anestésica puede ayudar enormemente a controlar la ansiedad del paciente, así como a hacer todo el proceso terapéutico menos doloroso. La elección correcta del anestésico local y del vasoconstrictor para un determinado paciente es muy importante (3). La lidocaína con epinefrina es el anestésico local más comúnmente usado en Cirugía Bucal, y además cuanto más elevada sea la concentración de vasoconstrictor asociado, mejor será el efecto hemostático, pero también será mayor el riesgo de provocar efectos cardiovasculares. Por este motivo, tiene especial interés monitorizar durante la intervención quirúrgica tanto a los pacientes sanos, como a aquellos con patología cardiovascular ya que, aunque la lidocaína 
al 2\% con epinefrina 1:80.000 no provoca cambios estadísticamente significativos ni en la presión arterial ni en la frecuencia cardíaca, en pacientes sanos durante la cirugía implantológica, no se pueden extrapolar estos datos a los pacientes cardiópatas o a los que toman antihipertensivos (3).

Por otra parte, el uso rutinario de antibióticos en los tratamientos implantológicos parece que está generalizado, sin embargo, la antibioticoterapia en la cirugía implantológica de pacientes sanos y su relación con el éxito o fracaso del tratamiento, está pobremente documentada. Sabemos que la infección puede ser una de las múltiples causas de fracaso de los implantes, pero cuando se toman las precauciones adecuadas, la profilaxis antibiótica parece ser innecesaria (4).

El éxito a largo plazo de los implantes dentales, entre otros factores, tiene su fundamento en un diagnóstico y un plan de tratamiento precisos. La planificación preoperatoria incluye el examen radiológico, que proporciona información relacionada con la localización de las estructuras anatómicas y la cantidad y calidad de hueso disponible para la colocación de los implantes.

Han sido muchos los autores que han intentado averiguar cuál sería la radiografía de elección para planificar un tratamiento de implantes. Así, Dearo de Morais y cols. (5) muestran en su estudio que la mayoría de profesionales consideran la tomografía computadorizada (TC) el método de diagnóstico por la imagen más fiable. A pesar de esto, su trabajo también demuestra que la mayoría de profesionales utilizan solamente la ortopantomografía asociada, en ocasiones, a otros métodos.

Para Kullman y cols. (6) la radiografía panorámica permite ver bien el contacto hueso-implante de forma tan fiable como las radiografías intraorales, aunque destaca que los dos métodos están sujetos a variabilidad inter o intraexaminador. La radiología nos permite obtener información de la calidad y cantidad de hueso, historia de traumatismos previos, cercanía de estructuras anatómicas importantes, necesidad de injertos o procedimientos quirúrgicos suplementarios, grado de vascularización y nivel de curación tisular (7).

La localización anatómica en la que se colocan los implantes también influye en el porcentaje de éxito, de manera que este porcentaje es superior en las zonas anteriores del maxilar superior y de la mandíbula que en las zonas posteriores (7). La porción anterior mandibular es el lugar de elección para la colocación de implantes inferiores, ya que su calidad ósea permite una buena estabilidad primaria, incluso en situaciones de atrofia severa, como sería el Síndrome Combinado de Kelly en el que, aunque un tratamiento tradicional con prótesis removible es todavía común, una solución implantosoportada tiene aquí una gran indicación (8). El grado de reabsorción de la cresta alveolar no depende de la edad del paciente, pero sí del tiempo que el paciente permanece edéntulo, por este motivo los implantes en esta zona anterior es mejor instalarlos lo antes posible después de la exodoncia para evitar una reabsorción excesiva (9).

Como hemos comentado, el tiempo que el paciente permanezca edéntulo influye en la reabsorción mandibular, pero no parece hacerlo en los cambios de densidad ósea que se producen con la edad. En un estudio realizado por Devlin y Horner (10), se concluye que estos cambios se dan independientemente de si el paciente está desdentado o no.

Un último aspecto que nos gustaría mencionar es el uso del láser en Implantología. Los láseres quirúrgicos tienen muchas aplicaciones relacionadas con el tratamiento con implantes, desde su instalación, hasta segundas fases quirúrgicas, manejo de los tejidos blandos y para el tratamiento de la periimplantitis (11). El principal punto de controversia radica en que el funcionamiento del láser necesita de la conversión de energía electromagnética en energía térmica, y la preparación del lecho implantario necesita de una técnica que no sobrepase los $47^{\circ} \mathrm{C}$ de temperatura en el hueso. Además, una vez colocados, la posibilidad de dañar la superficie del implante con la luz incidente del láser debe evitarse (11).

Una correcta restauración sobre implantes ofrece una satisfacción excepcional al paciente y al profesional. Se puede transformar una dentición enferma y antiestética en una dentición funcional y estéticamente agradable para el paciente. Hoy más que nunca, los pacientes piden sonrisas jóvenes y atractivas. La restauración o rehabilitación estética de un paciente con una dentición funcionalmente comprometida hace frecuentemente necesaria, una terapia multidisciplinar en la que, en muchas ocasiones, requiere del uso de implantes. Sin este enfoque multidisciplinar, los resultados finales pueden no ser los más óptimos $(12,13)$. 


\section{PACIENTES ESPECIALES}

\section{Enfermedad periodontal}

La colocación de implantes es una de las opciones para la restauración protésica en pacientes que han perdido los dientes debido a la disminución de su soporte óseo causada por la enfermedad periodontal, aunque debe tenerse en cuenta que una historia previa de este tipo de patología incrementa las posibilidades de fracaso de los implantes dentales. Basándonos en los estudios incluidos en esta revisión puede concluirse que, estos pacientes sufren más complicaciones y su tasa de éxito en consecuencia es menor. Una revisión reciente de la literatura, revela una relación positiva entre la tasa de supervivencia del implante, el nivel óseo periimplantario y la magnitud de la pérdida ósea periodontal (14). Hay, sin embargo, otros estudios que concluyen que las tasas de supervivencia de los implantes son similares en pacientes periodontales y sanos (15).

\section{Diabetes}

La diabetes mal controlada es un factor negativo para la supervivencia de los implantes. Una vez se ha producido el fracaso de un implante en pacientes diabéticos tipo II, se recomienda que el tiempo de espera para instalar de nuevo un implante en el mismo lugar, sea el suficiente para obtener la curación completa del hueso (16).

\section{Osteoporosis}

La osteoporosis no es una contraindicación absoluta para la colocación de implantes y tampoco lo es para la práctica de una técnica de aumento de la cresta alveolar, aunque en pacientes con esta patología también es predecible un mayor riesgo de complicaciones como: la reabsorción ósea, la no integración y un retraso en el tiempo de curación de los injertos de hueso, especialmente en el maxilar superior. Además, la probabilidad de la aparición de complicaciones aumenta en estos casos cuando coincide con el consumo del tabaco, así como el uso de corticosteroides y un abuso en el consumo de alcohol y cafeína (17). Aun así, respecto a la supervivencia del implante en relación con el consumo de tabaco en pacientes con osteoporosis y pacientes con una mineralización ósea normal, la única diferencia estadísticamente significativa que se encuentra es en áreas en las que hay poco hueso trabecular (17).

\section{Radioterapia}

Cuando hablamos de pacientes que requieren colocación de implantes, antes o después, de un tratamiento de radioterapia, basándonos en los resultados de estudios como los de Colella y cols. (18), el tiempo de instalación ya sea prerradioterapia o postradioterapia no está ligado a una mayor tasa de fracaso. Sin embargo, se observó un menor fracaso en la mandíbula comparada con el maxilar superior en este tipo de pacientes. Respecto a las dosis, se encontró una asociación de los fracasos de implantes con dosis totales mayores a $45 \mathrm{~Gy}$. Sin embargo no se ha podido establecer una relación significativa entre las dosis de radioterapia y la tasa de fracasos de los implantes (18).

\section{Patología ósea}

En patologías óseas como la osteogénesis imperfecta, la curación ósea es normal pero pobre en calidad. El objetivo primordial en estos pacientes es corregir las deformidades esqueléticas y prevenir las fracturas, por lo que, si los pacientes requieren algún tipo de procedimiento de Cirugía Bucal bajo anestesia general, se recomienda tomar precauciones debido a que existe predisposición a diferentes complicaciones, como fracturas patológicas o una hemorragia secundaria independientemente de la técnica que se practique (19).

\section{Otras patologías}

También podemos indicar la inserción de implantes endoóseos, en pacientes edéntulos con epidermólisis bullosa distrófica recesiva para lograr una mejora de su calidad de vida en comparación con las restauraciones protésicas tradicionales. Un estudio de Peñarrocha y cols. (22) concluye que los implantes pueden ser colocados y utilizados con éxito en este tipo de pacientes soportando prótesis dentales tanto fijas como removibles.

Respecto a la colocación de implantes en niños o adolescentes sus indicaciones y contraindicaciones están en relación con factores potencialmente desfavorables, como el posible traumatismo de gérmenes dentarios, la aparición de alteraciones de la erupción dentaria y variaciones multidimensionales del crecimiento craneofacial. Kramer y cols. (21) recomiendan la inserción de implantes en aquellos pacientes pediátricos que sufren una hipodoncia importante, como sucede 
en los pacientes que padecen displasia ectodérmica. El lugar más conveniente para su colocación parece ser la zona anterior mandibular; siendo recomendable evitar su inserción en el maxilar superior, o al menos en esta localización anatómica debe procurarse que las prótesis implantosoportadas no crucen la línea media (21).

\section{SUPERFICIES Y DISEÑOS DE IMPLANTES}

Con el progreso de las técnicas quirúrgicas, la ampliación de las indicaciones de los implantes o mejor dicho la disminución de sus contraindicaciones, aumenta el abanico de situaciones comprometidas con las que nos podemos encontrar. Eso justifica en parte el creciente interés en las investigaciones a nivel molecular o celular para mejorar o predecir los resultados sobre todo en los casos comprometidos.

En esta revisión hemos encontrado varios estudios que valoran el diseño del implante o la topografía de su superficie, algunos parecen repetitivos pero otros son innovadores.

Respecto a la relación entre la superficie y el hueso de calidad tipo IV, Grassi y cols. (22) demuestran que existe un mayor contacto hueso-implante con superficies tratadas con gravado ácido y arenado (SLA) respecto a la superficie mecanizada. Vallecillo y cols. (23) comparan los resultados obtenidos con implantes de superficies tratadas con espray de plasma de titanio (TPS) y otros recubiertos de hidroxiapatita (HA) colocados a nivel del maxilar superior y de la mandíbula de 21 pacientes. A los 5 años de carga no se observaron diferencias significativas entre los dos grupos en cuanto al sangrado mucoso y la profundidad del surco periimplantario pero sí una tasa de éxito más alta para los implantes recubiertos de HA.

Por otra parte, varios trabajos describen nuevas modificaciones de la microsuperficie implantaria. Park y cols. (24), en un estudio llevado a cabo en fémur de conejo reportan más contacto hueso-implante con superficies de titanio cubiertas de sustancias biológicamente activas como la T-CAM (molécula de adhesión celular) que con las superficies cubiertas de HA, ambas implantadas en hueso de baja calidad. Un mayor contacto hueso-implante también se ha descrito en un estudio de Goené y cols. (25), con superficies de titanio grabadas previamente a la incorporación de fosfato de calcio.
En un estudio sobre la absorción proteica y la diferenciación de precursores osteoblásticos en función de superficies modificadas químicamente, Protívinský y cols. (26) demostraron una mayor afinidad por la fibronectina en el caso de superficies grabadas con ácido comparadas con las mecanizadas y con otras también grabadas y luego expuestas a una solución de hidróxido de sodio (mayor actividad de osteocalcina, osteopontina y mayor adhesión de células osteoblásticas precursoras -hppm-).

Shibli y cols. (27), en un estudio microbiológico sobre gérmenes patógenos encontrados en las superficies de implantes no osteointegrados en pacientes fumadores, no hallaron diferencias significativas entre la mayoría de patógenos encontrados en superficies de diferentes rugosidades, lo que permite concluir que la colonización de una superficie rugosa no está en función de sus características particulares, o lo que es lo mismo, las superficies no se relacionan con la selección de gérmenes patógenos

Juodzbalys y cols. (28) presentaron un nuevo método para conseguir superficies de titanio rugosas similares a las superficies SLA pero sólo con grabado ácido. Con ello consiguieron una superficie significativamente más rugosa que las mecanizadas y casi similar a la superficie SLA.

En cuanto al diseño de implantes, McAllister (29) demostró que hay mejor preservación de tejidos interproximales a nivel del sector anterior, con implantes de plataforma festoneada que imitan la verdadera forma del cuello de los dientes naturales. Froum y cols. (30) defienden los implantes de pequeño diámetro (NDI) como alternativa para restauraciones en espacios estrechos sin recurrir a técnicas de aumento óseo ni a tratamientos ortodóncicos, tras obtener en su estudio una tasa de éxito del $100 \%$ a los 5 años de carga. En otro estudio prospectivo multicéntrico, Finne y cols. (31) también encontraron niveles estables del hueso marginal y de los tejidos blandos alrededor de implantes de pequeño diámetro y de una sola pieza tras un año de función con prótesis provisionales.

Pedroza y cols. (32) en un estudio comparativo sobre la resistencia a la compresión de tres diseños diferentes de implantes, encontraron que la conexión implante-pilar del sistema Unipost ${ }^{\circledR}$ (Tatum implant System, Global Dental Corporation,Waltham, EE.UU.) muestra una estabilidad mecánica superior comparado con el sistema Spline $®$ (Zimmer Implant System, Zimmer Dental Inc, Carlsbad, EE.UU.) que a su vez muestra una re- 
sistencia compresiva mayor que el sistema Screw Vent ${ }^{\circledR}$ (Zimmer Implant System, Zimmer Dental Inc, Carlsbad, EE.UU). El Unipost ${ }^{\circledR}$ se fracturaba siempre al mismo nivel, mientras que con los otros dos sistemas, la fractura ocurría a diferentes niveles de la conexión.

Parecen interesantes las conclusiones de Georgiopoulos y cols. (33) que en un estudio mediante análisis con elementos finitos, constatan que hay una tendencia a la reducción del estrés a nivel de la unión implante-cresta ósea marginal cuanto mayor es su longitud, antes y después de la osteointegración. Respecto al diámetro del implante no aconsejan utilizar uno mayor de $5 \mathrm{~mm}$ para las cargas inmediatas. Finalmente mencionan que el hueso cortical no está influenciado por la etapa de osteointegración pero si el hueso trabecular. En cambio, Bornstein y cols. (34) demuestran una buena integración tisular tanto en los implantes de plataforma ancha como estrecha.

También mediante análisis con elementos finitos Huang y cols. (35) encontraron que los implantes roscados no son capaces de disminuir el estrés a nivel de la cresta alveolar. Sin embargo a nivel de la interfase con el hueso, los implantes de rosca y los escalonados son capaces de disminuirlo

Por lo que se refiere al circonio, Bächle y cols. (36) investigaron la respuesta de osteoblastos cultivados sobre superficies de circonio de diferentes topografías. $\mathrm{El}$ interés hacia este biomaterial ha crecido gracias a su resistencia, su biocompatibilidad y su color. Al tercer día de cultivo se comprobó una mayor proliferación celular en las superficies tratadas comparándolas con superficies mecanizadas. No existieron diferencias a los 6 y 12 días. Oliva y cols. (37) concluyeron en su trabajo que los implantes de circonio con superficie rugosa pueden ser una alternativa real para sustituir dientes, aunque son precisos más estudios para confirmar este hecho de una forma clara.

\section{TEJIDOS BLANDOS}

Debido a las crecientes expectativas estéticas y funcionales que presentan actualmente los pacientes, el manejo de los tejidos blandos periimplantarios es una cuestión de vital importancia para lograr el éxito de los tratamientos.

La búsqueda de una arquitectura gingival que simule las papilas interdentales presentes en la dentición na- tural en pacientes que vayan a recibir una prótesis fija ceramo-metálica implantosoportada es un tema que despierta gran interés. Gallucci y cols. (38) estudiaron los cambios morfológicos que mostraba la mucosa alveolar tras la colocación de implantes cargados de forma inmediata con una prótesis provisional implantosoportada. Compararon la anatomía de la mucosa alveolar antes del tratamiento y tras 4 meses de llevar la prótesis provisional atornillada a los implantes. Concluyeron que la provisionalización inmediata conseguía moldear la mucosa alveolar, favoreciendo la creación de una morfología mucosa similar a papilas en los espacios intercoronarios de la prótesis.

Al margen de las técnicas no quirúrgicas, pueden emplearse diferentes tipos de injertos o colgajos para conseguir modelar la anatomía gingival y con ello dotar a la futura restauración protésica de un marco gingival más favorable. Peñarrocha y cols. (39) describen un colgajo de tejido conectivo para conseguir aumentar el grosor de corion en el sector anterior mandibular a la vez que se efectúa la colocación de implantes y la regeneración ósea vertical periimplantaria mediante el empleo de hueso autólogo particulado y membranas reabsorbibles. Como ventajas de esta técnica destacan la disminución del riesgo de dehiscencias de la herida, la consecución de todo el proceso en una misma intervención quirúrgica sin la necesidad de un lecho donante externo y la seguridad de supervivencia del injerto pediculado.

Los injertos libres son otra opción valida para mejorar el escenario mucoso periimplantario. A pesar de que los procedimientos quirúrgicos para llevarlos a cabo son simples y bien tolerados por los pacientes, se han descrito en la literatura diferentes complicaciones asociadas a ellos. Entre las más frecuentes se encuentran el sangrado excesivo del lecho donante, la pérdida del injerto por una pobre revascularización o diferencias en el color y la textura del injerto respecto al lecho receptor. No obstante, en ocasiones se describen incidencias menos comunes como la publicada por $\mathrm{De}$ Castro y cols. (40) tras la ejecución de un injerto gingival libre. Once meses después de la cirugía mucogingival detectaron una tumoración indolora asociada al injerto, que a la palpación drenaba un líquido mucoso amarillento. Tras la exéresis biopsia de la lesión, la anatomía patológica dictaminó que se trataba de un quiste por inclusión epitelial. Esta rara incidencia ya había sido publicada anteriormente por otros autores como consecuencia de injertos libres de tejido conectivo, sin embargo este es el primer caso descrito tras un injerto gingival libre. 
Nuevas herramientas, como los láseres, han irrumpido con fuerza en las distintas especialidades de la Odontología. En el terreno de la Implantología sus aplicaciones van desde la preparación de lechos óseos implantarios, pasando por la exposición de tapones de cierre durante las segundas fases quirúrgicas, hasta el tratamiento de la periimplantitis.

Todos los láseres utilizados en Odontología podrían emplearse para efectuar segundas fases quirúrgicas siempre y cuando se tenga especial atención en evitar dirigir el haz láser contra el cuerpo del implante. El láser consigue una precisa ablación de tejidos blandos, con una excelente curación postoperatoria y, con frecuencia, la única anestesia necesaria es la tópica. Entre las principales ventajas que presenta el láser en esta indicación destacaremos que obtenemos una correcta hemostasia, una fácil visualización del tapón de cierre, la formación de un coágulo protector que favorece la cicatrización de los tejidos y un alto grado de confort para el paciente tanto durante el procedimiento como en el curso postoperatorio (41). Por contra, la eliminación de mucosa queratinizada supone una desventaja trascendente, ya que podría poner en peligro el futuro mantenimiento de la salud periimplantaria.

\section{IMPLANTES INMEDIATOS}

Una de las ventajas de la colocación de implantes inmediatos es la minimización de la reabsorción ósea que se produce después de la exodoncia y la preservación de los tejidos blandos, permitiendo la posibilidad de crear una relación ideal entre el implante y los tejidos de soporte (42).

Esta técnica estaría indicada en el caso de fracturas radiculares, coronas no restaurables, reabsorción interna y externa de la raíz (43), fracasos endodóncicos $(42,43)$ y caries extensa subcrestal o fractura radicu$\operatorname{lar}(42)$.

Técnicamente, cuando se coloca un implante inmediato, se recomienda situarlo en la parte lingual/palatina del alvéolo y por debajo del nivel crestal, para compensar la reabsorción ósea esperada. También debe evitarse el contacto del implante a lo largo de la cara interna del hueso vestibular en los $5 \mathrm{~mm}$ coronales, y se debe dejar una distancia entre el implante y la cortical externa mayor de $2 \mathrm{~mm}$ (42).

En cuanto a la utilización del alvéolo como guía para la colocación del implante inmediato, debe tenerse en cuenta el eje del alvéolo, ya que la fresa tiende a seguirlo de forma natural y puede comprometer la localización y/o angulación final del implante (44).

Con respecto a la supervivencia de los implantes colocados inmediatamente después de la exodoncia Quirynen y cols. (44), realizaron un estudio donde valoraron 143 casos de forma prospectiva y 442 de forma retrospectiva, encontrando que para los implantes colocados tanto de forma inmediata como para los colocados en forma temprana/diferida, se obtuvo un fracaso del $5 \%$ (aproximadamente un 2,5\% antes de colocar la prótesis y del 2-3\% durante el periodo de función). La incidencia de pérdida de los implantes fue más alta cuando el implante se combinó con carga inmediata, especialmente en implantes con una superficie de rugosidad mínima (44).

Sin embargo, Orenstein y cols. (45), diseñaron un estudio piloto para valorar la estabilidad de un implante inmediato en la posición de un canino inferior con función inmediata, evaluada mediante la percusión electrónica (Periotest $(\AA)$, desde el día de la inserción del implante hasta el día 246. Encontraron que durante el primer mes, el complejo hueso-implante se hizo progresivamente menos estable, siendo el máximo nivel de inestabilidad a los 30 días, lo que correspondería al remodelado óseo (reabsorción-aposición), seguido de un período de estabilización progresiva que refleja la maduración de la integración. Estos autores concluyen que los aparatos de percusión electrónica poseen la capacidad de medir la movilidad y por lo tanto la estabilidad del complejo hueso-implante de una forma objetiva (45).

En los casos de colocación de implantes inmediatos con carga inmediata, es crucial obtener una buena estabilidad primaria o en caso contrario se producirá una excesiva movilidad que generará una cápsula fibrosa alrededor del implante. Entre los factores que afectan la estabilidad, se encuentran la densidad ósea, la geometría, la composición y superficie del implante y la habilidad del cirujano. Se deben hacer más estudios no invasivos para evaluar la repercusión de estas variables (45).

En cuanto a la influencia que puede tener la patología que ha motivado la extracción dentaria cuando se colocan implantes inmediatos, parece claro que ésta puede comprometer la osteointegración del implante. En general hay diversos artículos que señalan que la colocación de implantes en alveolos infectados (por patología endodóncica) no constituye un riesgo (44). 
Casap y cols. (46), hicieron un estudio en 20 pacientes con 30 implantes, colocados en alveolos postexodoncia a los que se les había practicado un legrado debido a la presencia de una infección periodontal, infección endoperiodontal, infección crónica periodontal, lesión periapical crónica o quistes periapicales. Los autores recomiendan el legrado meticuloso de los tejidos infectados y la ostectomía periférica del alvéolo además de una regeneración ósea guiada para aportar hueso sano alrededor del defecto alveolar, además de prescribir terapia antibiótica pre y postquirúrgica. El fresado para la colocación del implante, en los casos reportados, se extendió 3-4 mm más apical que el alvéolo para lograr estabilidad primaria. Los defectos óseos asociados de mayor tamaño se trataron con hueso bovino y una membrana de tetrafluoroetileno reforzada con titanio (Gore-Tex ${ }^{\circledR}$; WL Gore \& Associates Inc, Flagstaff, EE.UU.) para lograr el cubrimiento completo de los implantes. Todos los implantes evaluados se osteointegraron excepto uno y se hizo un seguimiento de 12-17 meses. El implante que fracasó estaba colocado en el maxilar superior y presentó movilidad después de la restauración provisional inmediata. Este resultado nos indica que, en este pequeño grupo de pacientes, el porcentaje de éxito es del 96-97\% (46). Este estudio cambia el concepto clásico respecto a la contraindicación de colocar implantes en un alveolo postextracción con infección y propone que, siguiendo un procedimiento controlado, los implantes inmediatos pueden ser colocados con éxito. La osteointegración dependerá de la eliminación de todos los tejidos contaminados y de la regeneración controlada del defecto alveolar (46). Sin embargo, otros autores señalan que hay una falta de evidencia científica del efecto de la patología ósea local residual respecto al éxito y supervivencia de los implantes inmediatos (44).

Actualmente, aún hay contradicciones concernientes al tiempo que debe transcurrir entre la exodoncia y la colocación del implante. Muchos estudios sostienen la predecibilidad de los implantes colocados en alveolos postextracción sin embargo, hay pocos informes que mencionen los límites de esta técnica. Basándose en este hecho, Funato y cols. (42) publicaron un artículo en el que volvieron a examinar las indicaciones especificas en función del intervalo de tiempo esperado entre la exodoncia y la colocación de los implantes inmediatos, lo que denominan "cuarta dimensión" (4D). Con este fin establecieron una clasificación:

- Clase 1: Exodoncia con colocación inmediata del implante.
- Clase 2: Exodoncia con colocación temprana del implante a las 6-8 semanas.

- Clase 3: Colocación diferida del implante a los 4-6 meses después de la exodoncia.

También proponen una clasificación según el tipo de alvéolo en el que se coloca el implante inmediato, basada en los niveles de tejido óseo y tejido blando que hay en el momento de la exodoncia:

- Clase 1: El hueso vestibular está intacto y hay un biotipo gingival grueso. La colocación del implante se efectúa sin incisión y sin colgajo.

- Clase 2: El hueso vestibular está intacto, el biotipo gingival es fino. La inserción del implante sin colgajo es viable, pero se combina con un injerto de tejido conectivo colocado inmediatamente, o en una segunda fase.

- Clase 3: Se ha perdido hueso vestibular, pero se puede colocar el implante en el hueso remanente del alvéolo, consiguiendo el soporte óseo necesario con una membrana de regeneración ósea guiada y añadiendo también injerto de tejido conectivo.

Dependiendo del grado de compromiso de la cortical vestibular, el caso podría diferirse, haciendo primero un procedimiento de aumento del reborde alveolar para instalar posteriormente el implante (42). En muchos casos, especialmente en biotipos finos, este último método dará un resultado más seguro y predecible. Concluyen que evaluar el biotipo periodontal puede ser muy útil para prevenir las complicaciones de los tejidos blandos en la colocación de implantes inmediatos (44).

Cuando aplicamos el concepto 4D (tiempo entre la exodoncia y la colocación del implante) en casos complejos en los que se insertan múltiples implantes en rebordes alveolares con defectos óseos, es muy importante efectuar extracciones seriadas de forma estratégica, ya que permite la colocación de una prótesis provisional fija, tiempo durante el cual se produce la reconstrucción de este reborde. Recomiendan seleccionar pilares dentales en sitios estratégicos para dar soporte a una restauración provisional parcial, seguidamente se haría la extracción de los dientes indicados y se espera a la cicatrización del tejido blando y del tejido óseo, para posteriormente colocar más implantes. Después de lograda la osteointegración, los implantes colocados en un segundo estadio, serán usados como soporte de una nueva restauración provisional o incorporados a la prótesis provisional inicial (42). 
Durante la colocación de los implantes, los dientes naturales remanentes también son usados como guías para determinar la posición vertical del implante. La altura del hueso interproximal de los dientes remanentes es el factor limitante para una restauración estética. Obviamente, es necesario que los pilares dentales sean relativamente estables para sostener una restauración provisional por lo que son un componente esencial en la elaboración de un plan de tratamiento de este tipo con implantes (42).

En cuanto a colocar implantes inmediatos en niños en crecimiento, podría considerarse una opción de tratamiento indicada en adolescentes que han perdido un incisivo debido a un traumatismo, pero debe tenerse en cuenta que los implantes osteointegrados, igual que los dientes anquilosados, no participan en los cambios que ocurren durante el crecimiento de los huesos maxilares (desplazamiento, remodelado, avance, etc.). El crecimiento facial del niño y aún el del adolescente, así como también la erupción continua de los dientes adyacentes, son factores de riesgo significativo, especialmente cuando se consideran la estética y la función (44).

Respecto a los implantes en la zona anterior, Cardaropoli y cols. (43) describieron un caso de una mujer de 21 años con un canino permanente retenido y el canino temporal en la arcada dentaria, esta paciente rechazaba un tratamiento ortodóncico para llevar el canino a su posición fisiológica y por lo tanto se decidió practicar la extracción del canino permanente y del canino temporal y colocar un implante inmediato. Se practicó la extracción preservando la cortical vestibular y se colocó un implante cónico con superficie tratada de $15 \mathrm{~mm}$ de longitud y $4 \mathrm{~mm}$ de diámetro a un torque de $32 \mathrm{Ncm}$. El defecto óseo palatino que correspondía a la corona del canino permanente fue rellenado con hueso de origen bovino (43). Debido a que se consiguió una buena estabilidad primaria del implante, los autores decidieron restaurar y dar función inmediata al implante con una corona provisional en ligera oclusión. Las ventajas de este procedimiento fueron evitar una segunda intervención quirúrgica y preservar las papilas contribuyendo a una mejor estética. Se observó una mínima pérdida ósea en los primeros meses de carga funcional así como una buena preservación de las papilas. Este caso apoya que la colocación de los implantes en la región anterior del maxilar superior inmediatamente después de la exodoncia mantiene tanto los tejidos blandos como los tejidos duros, creando una relación ideal entre el implante y sus tejidos de soporte (43).
Aunque la estética es frecuentemente citada como una de las razones para colocar implantes inmediatos (43, 44), se necesita más información sobre el resultado a largo plazo de este tipo de tratamiento. No hay datos suficientes sobre las complicaciones de los tejidos blandos, ni sobre la reabsorción de la cortical vestibular en los primeros meses después de una exodoncia. A la hora de seleccionar pacientes para la inserción de implantes inmediatos/tempranos, se deben considerar, tanto la posición del implante como la cantidad de tejido gingival (44).

\section{CARGA INMEDIATA}

En 1977 Bränemark, introdujo los principios de la osteointegración: la estabilidad primaria y la ausencia de micromovimientos. Clásicamente se creía que los implantes debían respetar un tiempo de osteointegración antes de desempeñar su función de soporte protésico, para prevenir la fibrointegración. Actualmente, es frecuente implementar la carga inmediata en los casos que presenten una geometría y calidad ósea adecuadas, ya que una carga inmediata controlada de los implantes no parece comprometer el proceso de osteointegración (47).

Los beneficios de la carga inmediata son una reducción del tiempo de tratamiento global y un menor número de intervenciones quirúrgicas, ya que los tejidos blandos curan a la vez que los tejidos duros. Además proporciona estética inmediata y ventajas psicológicas y funcionales respecto al uso de prótesis provisionales removibles (47-50).

Los criterios de inclusión y exclusión para este tipo de tratamiento no varían respecto a los escogidos para la carga convencional de los implantes dentales. Además, de acuerdo con el estudio de Davarpanah y cols. (51) se puede efectuar carga inmediata en pacientes de alto riesgo (higiene bucal escasa, enfermedad periodontal, bruxistas, fumadores, calidad ósea pobre, implantes inmediatos post exodoncia), asumiendo un índice de fracasos superior que en los casos en los que se hace carga diferida ( $13,4 \%$ frente a un $2-4 \%$ ), ya que los resultados globales obtenidos ( $100 \%$ éxito protésico a los 24 meses de seguimiento), continúan siendo altamente satisfactorios para los pacientes.

Se sabe que se pueden obtener resultados predecibles con carga inmediata, si se consigue suficiente estabilidad primaria. El grado de estabilización adecuada depende de tres variables importantes: el tipo 
de implante (diseño y superficie), la técnica quirúrgica (contacto inicial hueso-implante) y el tipo de hueso (calidad y volumen) (52). La mayoría de autores coinciden en que los implantes roscados logran una mayor estabilidad primaria y que las superficies rugosas mejoran y aceleran notablemente la osteointegración (48, 54) aunque la diferencia respecto a las superficies mecanizadas no es estadísticamente significativa $(51,53)$.

Oliveira y cols. (54) afirman que aplicar una técnica de condensación ósea durante el fresado del lecho implantario, proporciona un mayor contacto huesoimplante y una mayor densidad ósea, que se traduce en una mayor estabilidad primaria.

La decisión de realizar carga inmediata o no depende del grado de estabilidad primaria. El registro de esta estabilidad se puede obtener por diferentes métodos como: los valores del torque de inserción y el cociente de estabilidad del implante. Sin embargo, aún no se han podido identificar los valores adecuados para garantizar el éxito en la carga inmediata $(52,55)$. Shiigai (52) propone como seguros, los valores de torque de inserción de $\pm 43,2 \mathrm{Ncm}$ (rango de 32,5 a $46,2 \mathrm{Ncm}$ ) y de cociente de estabilidad del implante de \pm 71,8 (rango de 69,5 a 72,6). De acuerdo con los resultados obtenidos de su estudio, afirma que existe una correlación entre los valores elevados del torque de inserción y la supervivencia de los implantes. Mientras que los valores elevados del cociente de estabilidad del implante son menos indicativos, ya que son más susceptibles a fluctuaciones provocadas por la microrremodelación que se produce en la interfase entre el hueso y el implante.

Otro factor biomecánico importante que influye en el éxito del implante es la carga mecánica del hueso periimplantario. Normalmente, se admite un micromovimiento del implante $(47,48)$ de 50 a $150 \mu \mathrm{m}$ para no comprometer la osteointegración, aunque se desconoce la tolerancia exacta a este micromovimiento. Los factores que hay que tener en cuenta para reducir este micromovimiento son: el número, la distribución, la longitud y el diámetro de los implantes, la calidad ósea del paciente, la obtención de estabilidad primaria, la rigidez de la restauración, el control de las fuerzas oclusales y la distribución de la carga compresiva $(47,48$, 56). No existe un consenso entre los autores sobre el número de implantes necesarios para indicar carga inmediata en restauraciones múltiples (56); pero respecto a la longitud, la mayoría de estudios sugieren que los implantes deben tener al menos una longitud de $10 \mathrm{~mm}(47-51.53,56,57)$. Sin embargo, Degidi y cols. (58) presentan un estudio de 133 implantes cortos (longitudes de $6,5 \mathrm{~mm}$ a $10 \mathrm{~mm}$ ) con carga inmediata, obteniendo una tasa de supervivencia del $97,7 \%$ a los 4 años de seguimiento. Estos autores afirman, que la carga inmediata en implantes cortos es una opción de tratamiento válida en casos donde tengamos una altura ósea limitada. Pero que los implantes que tengan una longitud inferior a $10 \mathrm{~mm}$ y un diámetro más estrecho de $3,75 \mathrm{~mm}$, presentarán una reabsorción ósea marginal superior.

Otro factor importante para lograr una correcta osteointegración es el ajuste pasivo. Una prótesis mal ajustada provocará un micromovimiento excesivo de los implantes, que puede conducir a la pérdida de alguno de ellos. Longoni y cols. (48) proponen en su estudio un protocolo en el que utilizan un material de recubrimiento entre la prótesis híbrida provisional soportada sobre 6 implantes y las réplicas de titanio, con el objetivo de prevenir o al menos reducir, el estrés en los implantes producido por el desajuste entre éstos y la estructura metálica de la prótesis.

Existe gran controversia entre los autores en cuanto a la utilización de extensiones distales en las restauraciones protésicas. Hay autores que las evitan $(49,51)$ porque afirman que duplica la carga en los implantes distales, mientras que otros asumen esta carga $(47,48$, $56,59,60)$. En el punto en el que coinciden la mayoría de los autores $(47,48,56,59,60)$, es en que si la prótesis va a llevar extensiones distales, es fundamental que los implantes estén ferulizados. Akça y cols. (56) hicieron un estudio sobre cadáveres humanos comparando la tensión que soportan los implantes ferulizados y no ferulizados restaurados con sobredentaduras con carga inmediata. Estos autores concluyen que la ferulización de dos implantes intermentonianos (independientemente del tipo de prótesis), que soporten sobredentaduras con carga inmediata, reduce de manera estadísticamente significativa la tensión ósea en la cortical vestibular.

Jokstad y Carr (61) presentan una revisión sistemática de 1882 artículos sobre carga inmediata publicados entre 1990 y 2005, para comprobar si el momento de carga influye en el éxito a largo plazo del tratamiento con implantes. Una de las conclusiones a las que llegan es, que aunque el promedio de resultados está a favor de la carga diferida, las limitaciones de las poblaciones de estudio no permiten afirmar que los procedimientos de carga inmediata o temprana no sean un procedimiento seguro y una opción de tratamiento razonable. 
Cuando valoramos el éxito general del tratamiento, además de tener en cuenta el mantenimiento de la osteointegración a lo largo del tiempo, hay que comprobar que los tejidos periimplantarios (nivel de hueso marginal y contorno de los tejidos blandos) permanecen estables $(47,49,50,52,61)$. De Smet y cols. (47) analizan varios parámetros comparando los resultados obtenidos con carga diferida, temprana e inmediata, y concluyen que, aunque la pérdida de hueso marginal es prácticamente el doble en los grupos de carga inmediata y temprana a los 24 meses de seguimiento, ésta no constituye una diferencia estadísticamente significativa. Además, es importante tener en cuenta que en estos grupos se combinan la remodelación ósea por el proceso de curación ósea inicial y la carga mecánica durante los primeros meses.

Un medidor bioquímico relacionado con la formación y la reabsorción ósea es el nivel de nitritos presentes en el fluido sulcular periimplantario, resultantes de la oxidación del óxido nítrico. Tözüm y cols. (62) en un estudio en el que miden los niveles de nitritos en el fluido sulcular periimplantario, en función del tipo de carga observan que hay diferencias estadísticamente significativas, entre el grupo de carga inmediata y el grupo de carga diferida, y esto podría explicarse por qué se produce más reabsorción ósea marginal al efectuar carga inmediata. Hahn (49) y Noelken y cols. (50), defienden la utilización de implantes que incorporen el pilar transmucoso para hacer carga inmediata en implantes unitarios, ya que afirman que el hecho de que se produzca una curación del tejido periimplantario ininterrumpida, contribuye a una menor reabsorción ósea marginal $(-0,78 \pm 1,60 \mathrm{~mm}$ de hueso hasta la primera espira del implante tras 1 año de carga) y a una mejor conservación de los tejidos blandos.

De acuerdo con la revisión sistemática de Jokstad y Carr (61) la mitad de los estudios revisados analizan implantes en el área intermentoniana. Por lo que podemos considerar que la carga inmediata en estos implantes es una alternativa razonable a la carga diferida. Chiapasco y cols. (57) presentan un estudio clínico en 6 pacientes con mandíbula atrófica, donde realizan injertos de calota craneal y tras 8 meses de curación del injerto colocan un total de 23 implantes intermentonianos con carga inmediata. Tras 24 meses de seguimiento obtienen una tasa de éxito del 95,7\% y una tasa de supervivencia del $100 \%$, similares a los resultados obtenidos en estudios de carga inmediata sin injertos, e incluso con carga diferida. Por lo tanto, concluyen que los resultados serán más predecibles si se espera el periodo de osteointegración del injer- to antes de colocar los implantes. Lambrecht y Hodel (59) presentan un estudio retrospectivo donde analizan los resultados obtenidos a largo plazo (seguimiento medio de 12,2 años) en 44 pacientes rehabilitados con un total de 176 implantes intermentonianos restaurados con sobredentaduras sobre barras con una tasa de éxito del 83,3\%. Así mismo, Degidi y cols. (60) presentan un estudio retrospectivo de 200 implantes intermentonianos con carga inmediata durante un periodo de seguimiento de 43 meses donde obtienen una tasa de supervivencia del $100 \%$ y concluyen que los implantes con una longitud $\geq 13 \mathrm{~mm}$, un diámetro > 3,75 mm tipo Frialoc ${ }^{\circledR}$ (Dentsply Friadent, MannheimFriedrischeld, Alemania) y XiVE TG ${ }^{\circledR}$ (Dentsply Friadent, Mannheim-Friedrischeld, Alemania) presentan menor reabsorción ósea y por lo tanto mejores resultados a largo plazo.

Finalmente, de acuerdo con Jokstad y Carr (61), a pesar de existir un gran número de publicaciones sobre carga inmediata, la falta de estudios clínicos randomizados, con periodos de seguimiento relativamente cortos y la gran diversidad en cuanto a la metodología de los estudios, no nos permiten obtener conclusiones definitivas para elaborar protocolos clínicos sobre carga inmediata. Se requiere estudiar mejor las características de las superficies de los implantes, la carga inmediata en los edentulismos parcial y total. Sin embargo, debido al gran número de artículos publicados sobre el tema, podemos considerar que la carga inmediata en los implantes intermentonianos en las condiciones adecuadas es una alternativa razonable a la carga diferida.

\section{COMPLICACIONES EN IMPLANTOLOGÍA}

La colocación de implantes dentales es un procedimiento seguro, sin embargo, pueden surgir algunas complicaciones en los tratamientos.

El hematoma sublingual es una complicación intraoperatoria rara, pero potencialmente letal. Es consecuencia de una hemorragia de los vasos linguales perimandibulares, debido a la perforación de la cortical lingual durante el fresado del lecho implantario. Esta hemorragia puede infiltrarse por los tejidos del suelo de la boca, por lo que se recomienda efectuar inmediatamente una compresión bimanual y trasladar al paciente al Servicio de Urgencias de un centro hospitalario debido a la posibilidad de que el hematoma ocasione una obstrucción de las vías aéreas superiores. 
El daño potencial de los vasos sanguíneos del suelo de la boca, depende de la morfología ósea de la zona mandibular a intervenir, del diámetro del vaso y de la longitud del fresado. Por este motivo, la morfología ósea debe de ser bien estudiada particularmente en mandíbulas atróficas valorando la angulación de la cortical lingual y la forma y posición de la fosa sublingual, siendo estos factores los que determinaran la inclinación del implante. Un estudio anatómico realizado en 12 cadáveres humanos ha sido muy útil para tomar conciencia del riesgo y ha permitido verificar que la distancia vertical desde la cresta alveolar a los vasos variaba de 2 a $26 \mathrm{~mm}$ y la distancia horizontal de los vasos sanguíneos a la cortical lingual de 1 a 9 $\mathrm{mm}(63)$

Por primera vez El-Naaj y cols. (64) describen dos casos clínicos de pacientes portadores de implantes en los cuales se desarrolló un carcinoma de células escamosas. Los autores consideran que la asociación implantes/carcinoma es rara y la justifican por la posible migración sulcular de las células tumorales de un tumor a distancia hacia la zona donde están colocados los implantes. Uno de los pacientes presentaba una lesión precancerosa (liquen plano) y el otro presentaba antecedentes de cáncer tiroideo y de mama.

Chee y Jivraj (65) han publicado un artículo analizando los principales fracasos y complicaciones que pueden ocurrir tras la colocación de implantes. La mayoría de estos fracasos puede ser prevenidos seleccionando correctamente los pacientes y aplicando un plan de tratamiento adecuado. Los autores clasifican estas complicaciones en: pérdida de la osteointegración, siendo el maxilar superior y los injertos óseos las zonas más susceptibles; la colocación del implante en una posición incorrecta y los problemas biomecánicos.

Los implantes, al igual que los dientes, pueden presentar patología en la zona apical, caracterizada por supuración, fístula y pérdida de hueso alveolar. La literatura recomienda el tratamiento antibiótico, la detoxificación del implante o su remoción. Balshi y cols. (66) presentan un estudio practicado sobre 39 implantes con imagen radiotransparente apical que se trató mediante la exéresis de la parte apical afectada del implante, manteniendo su porción osteointegrada y la prótesis que soportaba. Con esto lograron la resolución del problema en 38 casos (seguimiento de 15 años). Los autores opinan que las principales causas de estas lesiones periapicales son: la infección bacteriana de dientes adyacentes o extraídos, el sobreca- lentamiento del hueso durante el fresado para la colocación de implantes largos y con irrigación externa, las microfracturas del hueso por sobrecarga oclusal y la creación de cavidades residuales debido a la colocación de implantes más cortos que la longitud del lecho preparado. Insisten que es crucial tratar la lesión antes de que esta avance y afecte a la porción coronaria.

Es importante recordar que los implantes solamente sustituyen el diente natural y que la interfase implante-mucosa-hueso es una aproximación al periodonto natural. La ausencia de cemento y de ligamento periodontal, la vascularización y los fibroblastos escasos, la orientación paralela del tejido conectivo supracrestal y la localización subgingival de la corona son factores que convierten el implante más susceptible al desarrollo de la inflamación y la pérdida ósea cuando se expone a la invasión bacteriana y a la acumulación de placa. La identificación temprana de los signos y síntomas de la pérdida ósea es esencial para prevenir la pérdida del implante. En un estudio donde analizaron los factores que causan pérdida ósea alrededor de los implantes, concluyen que ésta está asociada a los implantes cortos, anchos, a los que soportan prótesis fija y los colocados en pacientes fumadores. Sin embargo, los mismos autores refieren que el tipo de implante y de superficie, la dentición antagonista y la cantidad de mucosa queratinizada no afectan significativamente a esta pérdida (67).

La periimplantitis se considera una enfermedad inflamatoria que afecta a los implantes osteointegrados en función y que provoca la pérdida de su soporte óseo. Muchos aspectos de su patogénesis son aún desconocidos. Actualmente, se considera que su origen y perpetuación son debidos a un pequeño grupo de bacterias anaerobias Gram negativo o microaerófilas que colonizan el área subgingival. Las bacterias causan la destrucción tisular directamente a través de sus productos tóxicos e indirectamente activando sistemas de defensa en el hospedador. Liskmann y cols. (68) han publicado un estudio que pretende valorar los niveles de los antioxidantes que existen en la saliva, para permitir identificar las diferencias entre la saliva de los pacientes con tejidos periimplantarios sanos y de los pacientes con periimplantitis. Concluyen que la cantidad total de antioxidantes en la saliva y las concentraciones de ácido úrico y ascorbato, que son los principales antioxidantes salivares, están significativamente disminuidos en pacientes afectados por periimplantitis. Justifican la importancia de estos hallazgos y recomiendan la administración de suplementos antioxidan- 
tes en combinación con una terapia interceptiva en el tratamiento de esta enfermedad implantaria.

La eliminación de la lesión inflamatoria, la detención de la progresión de la enfermedad y el mantenimiento de la función del implante con los tejidos periimplantarios sanos, son los objetivos principales del tratamiento de la periimplantitis.

La utilización del instrumental manual, como las curetas y los ultrasonidos, no son considerados totalmente eficaces en la remoción del tejido de granulación y en el desbridamiento de la superficie del implante, debido al daño que provocan en la superficie de titanio, lo que puede interferir posteriormente con el proceso de cicatrización ósea. En un estudio a boca partida que tenía como objetivo valorar los efectos del láser de Er:YAG respecto de la cureta de plástico en el desbridamiento de la superficie del implante en perros, a los cuales se indujo experimentalmente una periimplantitis, los autores concluyeron que es más difícil llevar a cabo el tratamiento convencional en comparación con el láser, principalmente en el espacio estrecho que queda entre el implante y el hueso o entre las espiras del implante y también porque el poder de descontaminación del láser es superior. Refieren que no se ha observado macroscópicamente daño térmico ni mecánico causado por la irradiación láser a $10 \mathrm{~J} / \mathrm{cm}^{3}$ por pulso y $20 \mathrm{~Hz}$ con espray de agua. El tratamiento implementado con el láser de Er:YAG induce un mayor sangrado, posiblemente debido al bajo efecto térmico de este láser, pero este sangrado influye en la cicatrización de forma positiva, promoviendo la neoformación ósea (69).

Otro estudio clínico (70) con un seguimiento de 5 años compara el tratamiento de los defectos óseos causados por la periimplantitis utilizando la fase pura del fosfato tricálcico ß en combinación con el láser de $\mathrm{CO}_{2}$ - el tratamiento convencional. Según este estudio, a largo plazo, los efectos bactericidas de la irradiación láser no son superiores a los de la descontaminación convencional cuando este tratamiento se combina con el aumento óseo. Además se constata que la irradiación del láser no puede prevenir la reinfección. Sin embargo, se ha observado que la descontaminación con el láser de $\mathrm{CO}_{2}$ es más eficaz en defectos óseos estrechos y profundos, especialmente cuando se acompaña de la resección de los tejidos blandos. Takasaki y cols. (69) defienden la utilización del láser de Er:YAG argumentando que el de $\mathrm{CO}_{2}$, aunque tenga la capacidad de ablacionar el tejido de granulación, presenta el riesgo de dañar la superficie de titanio del implante y del hueso adyacente debido a las altas temperaturas alcanzadas durante la irradiación.

El láser de diodos también es eficaz para la descontaminación de la superficie del implante. SennhennKirchner y cols. (71) investigaron los efectos de la descontaminación de cinco diferentes programas de irradiación de dos tipos de láser (uno emitiendo luz a una longitud de onda de $810 \mathrm{~nm}$ y el otro a $980 \mathrm{~nm}$ ) en "biofilms" intraorales sobre superficies rugosas de titanio. Los resultados probaron la eficacia de ambas longitudes de onda en cuanto a la reducción del "biofilm" producido por las bacterias aerobias.

En un estudio experimental donde se indujo una periimplantitis en perros (72) se probó la utilización de un injerto óseo en combinación con fibrina rica en plaquetas para el tratamiento de esta enfermedad.Justifican la utilización de esta mezcla, porque la fibrina contiene un gran número de plaquetas que liberan cantidades significativas de factores de crecimiento, conocidos por favorecer la formación ósea. Además, contiene altas concentraciones de fibrinógeno que tiene la capacidad de producir una malla de fibrina con una fuerza adhesiva suficiente para aguantar las partículas óseas en una determinada configuración. Los resultados de este estudio muestran que la osteointegración es significativamente superior en los defectos tratados con la combinación de hueso autólogo con la fibrina rica en plaquetas, presentando una media de contacto hueso-implante del 50,1\%, mientras que en el grupo de los defectos tratados solamente con el injerto óseo, la media fue de 19,3\%.

Pongnarisorn y cols. (13) determinaron en un estudio experimental con perros la naturaleza del infiltrado inflamatorio asociado a diferentes superficies de implantes. Todos los implantes tenían superficies rugosas de óxido de titanio pero diferían en la superficie de la porción transmucosa grabada con los ácidos hidrofluorídrico y nítrico, titanio pulido, superficie oxidada y otra con una ranura circunferencial. Observaron que los infiltrados inflamatorios se encuentran principalmente a nivel subepitelial y perivascular y que las células $\mathrm{T}$ son las predominantes. Los resultados sugieren que el desarrollo de la inflamación es independiente del tipo de superficie de los implantes, sin embargo, está asociada a la presencia de placa bacteriana. Aunque parezca que no existe una asociación entre los diferentes tipos de superficie de implantes y el tipo de microorganismos peri-implante, si que se ha verificado mayor filtración en implantes que presentaban una ranura circunferencial en la porción 
transmucosa debido al mayor acumulo de placa bacteriana en esa zona.

\section{REGENERACIÓN ÓSEA GUIADA}

Los contínuos avances de las técnicas de regeneración ósea guiada (ROG), han incrementado de forma considerable las opciones de tratamiento en el campo de la Implantología bucofacial.

Algunos autores afirman que la regeneración ósea con diferentes materiales influye directamente en el contacto entre el hueso y la superficie de los implantes $(74,75)$. Simion y cols. (76) presentan un estudio en perros, donde tratan defectos óseos crónicos con regeneración ósea y colocación de implantes. Consiguen un aumento considerable del reborde alveolar, sin embargo no logran una buena osteointegración, ya que en la mayoría de los casos encuentran zonas de tejido conectivo denso entre el implante y el hueso; dato que no concuerda con estudios previos efectuados en humanos y en animales.

Actualmente están en estudio nuevas técnicas de ROG, una de ellas es la utilización de miniplacas de osteosíntesis o membranas de politetrafluoroetileno expandido (PTFEe), en combinación con injertos óseos autólogos. Hay un estudio en el que se comparan las ventajas y desventajas de cada técnica y se concluye que no existe ninguna diferencia estadísticamente significativa entre ellas, por lo tanto es el especialista quien tiene que decidir cuál es la más adecuada de acuerdo con las características del paciente (77).

Bilir y cols. (78) presentan un estudio con membranas reabsorbibles de ácido poliláctico y membranas de colágeno (donde demuestran que las células osteoblásticas humanas son capaces de proliferar y establecerse en estos dos tipos de membranas; aunque creen que las membranas de colágeno limitan las funciones osteoblásticas, a causa de la reducida proliferación que observan en el recuento de células durante las 24 y 72 horas, en comparación con otros tipos de membranas.

Algunos autores propugnan el desarrollo de técnicas menos invasivas en la ROG. Una de ellas, consiste en hacer una pequeña incisión vertical de espesor total, creando un túnel, en el cual se coloca una sonda de Foley con un balón que se expande para crear un espacio en el que se pueda colocar la membrana y el material de injerto (en este caso fue una mezcla de fibrina y sustituto óseo), consiguiendo un aumento vertical de 2,4 a 5,1 mm y horizontal de 1,3 a 3,9 mm. Esta técnica está indicada en casos de atrofia del reborde residual en los cuales no es posible la colocación de implantes por problemas estéticos o funcionales (79).

Otra posibilidad a considerar es la aplicación de técnicas de ROG después de la extracción de un diente con infección. Kfir y cols. (80) en su estudio afirman que es una opción de tratamiento fiable y segura, ya que no se produjeron infecciones, exposición de las membranas, ni fue necesaria una ROG adicional en ninguno de los pacientes.

Otros autores proponen modificar la técnica quirúrgica durante la colocación de implantes, para obtener hueso autólogo. Podemos recolectar partículas de hueso durante el proceso de fresado del lecho del implante, con la ayuda de un filtro de hueso conectado al sistema de aspiración durante la ostectomía (81). Anitua y cols. (82) proponen efectuar el fresado a bajas revoluciones, para mantener el lecho óseo en mejores condiciones biológicas, y favorecer la inserción del implante. Se ha demostrado microscópicamente que el hueso recolectado durante este procedimiento, es hueso vivo, sin embargo hay estudios que demuestran que este hueso puede inducir la contaminación bacteriana y aunque el protocolo quirúrgico sea lo más riguroso posible, la reducción de las bacterias será incompleta. Por lo tanto, debemos aplicar esta técnica con cautela para disminuir la contaminación bacteriana al máximo (83).

Hoy en día intentamos preservar el espacio y la forma de los alveolos en localizaciones donde la estética es muy importante, pero para conseguir esta preservación la exodoncia debe ser lo más atraumática posible. Otra opción recomendada para no perder volumen óseo, es rellenar el alveolo con materiales de injerto o aumentar el tejido gingival durante la fase de colocación de los implantes (84).

Existen nuevas líneas de investigación que se centran en materiales que ayuden a la ROG. Uno de ellos es el ipriflavone (IP), derivado de la soja, que tiene importantes efectos sobre el metabolismo óseo. En un estudio en conejos, en el que se hacían tres grupos (sin IP, IP antes de la cirugía, IP después de la cirugía), se realizaron dos surcos (con trefinas) en el hueso parietal de los conejos, se colocaron tapones hemisféricos estandarizados de titanio y se hicieron estudios histológicos e histomorfométricos. Los resultados demostraron que la administración del IP (antes o después de la intervención quirúrgica) mejora la calidad del hue- 
so neoformado y que existe una relación dosis-dependiente (85).

Por último, otro factor importante en la cirugía implantológica es disponer de una buena cantidad de tejido conectivo. Un estudio que investiga el uso de la matriz dérmica acelular (MDA), demuestra que ésta se integra totalmente en el tejido conectivo a los 12 meses, por lo que es un sustituto óptimo para los injertos conectivos (86).

\section{ELEVACIÓN DEL SUELO DEL SENO MAXILAR (SINUS LIFT)}

La elevación del suelo del seno maxilar es un procedimiento quirúrgico destinado a incrementar el volumen óseo en la zona posterior del maxilar superior, cuando el hueso alveolar presenta una altura insuficiente para la instalación de implantes dentales. El objetivo de esta técnica es elevar la membrana sinusal y colocar un injerto entre la membrana y el suelo del seno maxilar para incrementar el volumen de la cresta ósea (87).

El tipo de material de injerto utilizado está en función de la técnica de elevación del seno maxilar que se aplique. Ya sea con el abordaje clásico de CaldwellLuc mediante la preparación de una ventana lateral o con la técnica de Summers de abordaje alveolar mediante osteótomos, es preciso obtener hueso autólogo intraoral o extraoral y emplean distintos substitutos óseos, como el injerto de hueso desmineralizado deshidratado-congelado, la hidroxiapatita bovina, los gránulos de cristal bioactivo, sulfato cálcico y los factores de crecimiento empleados como elemento único o junto con hueso autólogo (87).

En un estudio de Wallace y cols. (88) se utiliza la técnica de elevación del suelo sinusal con osteótomos limitándose su indicación a los casos en los que se pretendía ganar una altura máxima de $3 \mathrm{~mm}$, ya que según los autores, esta técnica no está indicada para elevar la membrana sinusal más de $5 \mathrm{~mm}$.

Una variable a considerar es la decisión de colocar implantes en la misma intervención quirúrgica que el injerto, o seguir la técnica en dos fases con un periodo de curación intermedio. En la técnica simultánea, el hueso alveolar residual de la zona donde se colocarán los implantes debe medir al menos $4 \mathrm{~mm}$ de altura, para asegurar su estabilidad primaria. Cuando no puede predecirse una buena estabilidad primaria por la ausencia de una suficiente altura ósea la técnica debe practicarse en dos tiempos. Las desventajas de este último procedimiento son el largo periodo de cicatrización y la necesidad de una intervención quirúrgica adicional. A favor de esta técnica en dos fases encontramos un estudio en animales de experimentación (monos), que ha revelado que retrasar la colocación de los implantes 4 meses después del aumento sinusal permite obtener un elevado índice de hueso mineralizado en contacto con el implante (87).

En un estudio de Becktor y cols. (89) en pacientes que presentaban una altura ósea remanente menor de 5 mm se practicó una elevación sinusal mediante un injerto autólogo en bloque estabilizado con la colocación de los implantes simultáneamente o en dos fases. Para el abordaje en dos fases el injerto se estabilizó mediante tornillos de osteosíntesis de 7-15 mm de longitud y 2 $\mathrm{mm}$ de diámetro. El periodo de consolidación fue de 37 meses. Se perdieron 6 de los 69 implantes colocados en 17 pacientes, todos ellos antes de colocar la prótesis, y la mayoría pertenecían al grupo en que se practicó la técnica en una fase. Biológicamente es mejor la técnica en 2 fases ya que facilita la vascularización, maduración e integración del injerto. Aunque, la técnica de una fase es menos invasiva, con ventajas en cuanto a coste y tiempo (89). El hueso autólogo es el de elección por su capacidad osteoinductiva, compatibilidad y los resultados clínicos satisfactorios que consigue (90). En cambio, las ventajas del uso del hueso aloplástico son la reducción del tiempo operatorio y porque elimina la posible morbilidad de la zona donante (91).

En otro estudio en 16 pacientes se compararon mediante histomorfometría, injertos de hueso autólogo particulado de calota craneal con los de cresta ilíaca en los procedimientos de elevación del seno maxilar. La cantidad de hueso remanente debía ser menor de $2 \mathrm{~mm}$ (clase V de Cadwood y Howell). Se excluyeron los pacientes fumadores y aquellos que presentaban enfermedades sistémicas. El tiempo de integración del injerto fue de 5 meses, momento en el que se tomó una muestra ósea con trefina para su estudio. Se consideró hueso vivo al tejido óseo mineralizado y vascularizado. El hueso no vital era aquel tejido óseo mineralizado pero con lagunas de osteocitos vacías. La suma de ambos porcentajes daba como resultado el porcentaje total de tejido óseo, con respecto al volumen total de tejido. Encontraron mayor morbilidad en forma de dolor postoperatorio en el grupo de la cresta ilíaca. Existe discusión acerca del comportamiento de los injertos en cuanto a su potencial de reabsorción, ya sea por su origen embrionario, endocondral o intramembranoso, o bien por su estructura intrínseca, cor- 
tical o esponjosa. El hueso intramembranoso podría tener menos reabsorción, no por su origen embriológico sino porque posee una mayor proporción de hueso cortical. La estructura sólida del hueso cortical ayudaría a que el injerto tarde más en reabsorberse y tenga mayor supervivencia que los injertos de hueso esponjoso. El estudio histomorfológico concluye que los injertos de hueso trabecular de calota craneal proveen una mayor cantidad de hueso total y de hueso vital que los de cresta ilíaca (92).

La combinación de los injertos óseos con los factores de crecimiento presentes en el plasma rico en plaquetas (PRP) se considera actualmente un elemento útil para mejorar la formación de nuevo hueso. Sin embargo, un trabajo publicado por Schlegel y cols. (93) concluye que no observaron ningún efecto positivo en el grupo tratado con PRP. El PRP no fue osteoinductivo, aunque consideran que podría ser "osteoproductivo" usado en conjunto con partículas de hueso autólogo vivo en pacientes a los que se practicó una elevación del suelo del seno maxilar.

Existe un creciente interés por el uso de la cola de fibrina. Ésta ayuda a mantener unidas las partículas del injerto, y además la presencia de plaquetas acelera el proceso de curación al liberar los factores de coagulación de las plaquetas al ser activadas por la trombina. La cola de fibrina se prepara mezclando las soluciones de fibrinógeno y trombina en proporción de 3:1. La cantidad de fibrinógeno que contiene es 12 veces mayor que en el PRP y la concentración de factores de crecimiento 8 veces mayor. Cuando se enriquece con plaquetas mejora tanto la osteointegración de los implantes como la altura del hueso regenerado a los 6 meses después de la intervención quirúrgica (94).

En una evaluación histológica practicada por Iezzi y cols. (95) concluyeron que el sulfato de calcio (CaS Surgiplaster Sinus, Classimplant, Roma, Italia) se reabsorbe rápidamente y es reemplazado por hueso nuevo que entra en contacto directo con el implante sometido a carga inmediata en casos de regeneración ósea sinusal.

Li (96) estudió las diferencias en cuanto a la capacidad osteogénica entre la proteína ósea BMP recombinada-2/ACS (esponja reabsorbible de colágeno) y el injerto de hueso autólogo en 190 elevaciones del seno maxilar. Las BMP favorecieron una osteoinducción que generó hueso trabecular inmaduro sobre el hueso preexistente, que posteriormente se remodeló para formar hueso trabecular maduro. El injerto de hueso au- tólogo indujo osteoconducción que generó un nuevo hueso medular entre los gránulos del injerto óseo autólogo acelular para ser más tarde substituido por hueso lamelar trabecular. En este estudio el autor concluyó que la proteína ósea BMP recombinada-2/ACS (esponja reabsorbible de colágeno) y el injerto de hueso autólogo clínicamente eran similares pero que el proceso de la osteogénesis resultaba ser histológicamente diferente.

Teniendo en cuenta la superficie de los implantes, se ha constatado que cuando se instalan en crestas óseas resultantes de elevaciones sinusales, los implantes rugosos presentan un mayor índice de supervivencia en comparación con los implantes mecanizados, además de que obtienen un mayor contacto hueso-implante que los mecanizados. El objetivo del estudio de Marchetti y cols. (87) fue evaluar el éxito de los implantes a 1 y 5 años, después de cargarse prostodóncicamente en zonas donde se había efectuado un aumento óseo sinusal mediante un acceso lateral, utilizando como material de relleno una mezcla de hueso autólogo y hueso inorgánico bovino (Bio-Oss®; Geistlich Pharmaceutical, Wolhusen, Suiza). Los parámetros que se tuvieron en cuenta para evaluar el éxito de osteointegración de los implantes fueron: protocolo de implantes (inmediato versus 2 tiempos quirúrgicos), tipo de superficie del implante (rugoso o mecanizado) y longitud del implante. El número de implantes fracasados con superficie mecanizada fue más alto que el número de implantes con superficie rugosa, pero esta diferencia no fue estadísticamente significativa. El diámetro más comúnmente utilizado en implantes mecanizados fue de $3,75 \mathrm{~mm}$ presentando un fracaso del 10,8\%. Según la longitud del implante, los de 10 y $18 \mathrm{~mm}$ no presentaron ningún fracaso; los de $13 \mathrm{~mm}$ presentaron un 7,6\% de fracasos y los de $15 \mathrm{~mm}$ presentaron un $1,8 \%$ de fracaso. La técnica quirúrgica estaba significativamente asociada al implante fracasado desde la colocación del implante hasta los 5 años siguientes. Los implantes colocados con la técnica de una sola fase mostraron un elevado índice de fracaso $(12,5 \%)$ en comparación con los implantes colocados siguiendo la técnica en dos fases $(2,8 \%)$. Este estudio concluye que la elevación sinusal con una mezcla 70/30 de hueso autólogo e hidroxiapatita bovina inorgánica es un procedimiento con un elevado índice de éxito (87).

Stavropoulos y cols. (97) también hicieron un estudio comparativo entre implantes totalmente tratados (mediante grabado ácido) y parcialmente tratados con $2 \mathrm{~mm}$ de superficie mecanizada en el extremo coronal. La elevación sinusal fue efectuada por vía transalveolar con 
osteótomos y el injerto elegido fue hueso autólogo de mentón extraído mediante trefina, particulado y mezclado con cristales bioactivos (Biogran $®$, Orthovita, Malvem, EE.UU.) en proporción 1/1. Los implantes se colocaron en una segunda fase. Tras un año de control concluyeron que no había diferencias en los parámetros evaluados entre implantes totalmente y parcialmente tratados colocados en elevaciones de seno maxilar.

En la literatura se han descrito complicaciones durante y después de la colocación de injertos sinusales (98). La complicación intraoperatoria más frecuente es la perforación de la membrana de Schneider con una incidencia de entre $14 \%$ y $56 \%$ (88).

Esta complicación se asocia con la presencia de un septo intrasinusal que dificulta la elevación de la membrana de Schneider. Según el estudio de Shibli y cols. (98) el septo divide el seno maxilar en distintos compartimentos y presenta diferentes alturas y orientaciones. La prevalencia del septo maxilar en ambos senos en pacientes parcial y totalmente edéntulos es del $16 \%$ y el $31,7 \%$ respectivamente. Es importante conocer toda la información disponible a este respecto antes de iniciar cualquier intervención quirúrgica. Se ha demostrado que la mejor radiografía para detectar los septos del seno maxilar es la tomografía computadorizada (TC).

El uso de un aparato generador piezoeléctrico (Piezosurgery Inc. $®$ ), Matawan, New Jersey, EE.UU.) diseñado para practicar osteotomías sin dañar los tejidos blandos adyacentes, disminuye la incidencia de perforaciones de la membrana sinusal. Wallace y cols. (88) presentan los resultados obtenidos en 100 casos consecutivos de elevación de seno maxilar mediante Piezosurgery $®$, en los que se evidenciaron sólo 7 perforaciones. Todas las perforaciones que aparecieron empleando esta tecnología se presentaron durante la instrumentación manual. Además comentan que, el uso del Piezosurgery $®$ evita la posibilidad de lesionar los vasos que discurren por la pared lateral del seno, previniendo así complicaciones hemorrágicas. También presenta como otras ventajas: mejor visibilidad intraoperatoria, menor sangrado peroperatorio y menor traumatismo quirúrgico (88).

\section{TÉCNICAS AVANZADAS}

Existen muchas técnicas quirúrgicas que nos permiten un mejor manejo de los pacientes que presentan un insuficiente soporte óseo, ya sea por excesiva atrofia debida a exodoncias prematuras, a secuelas de trau- matismos faciales o por exéresis quirúrgica de quistes y neoplasias. Estos casos pueden ser tributarios de técnicas de cirugía avanzada acompañadas de la colocación de implantes dentales.

Una de las técnicas que se está utilizando es la colocación de implantes dentales en el cúbito del antebrazo para posteriormente, ser transplantados a la región bucal donde es preciso aumentar el volumen de hueso maxilar y restaurar los dientes perdidos. Se realiza una primera intervención quirúrgica en la que se instalan los implantes en el cúbito y en un segundo tiempo quirúrgico se procede a extraer el bloque óseo que contiene los implantes y se procede a transplantarlo a la región deseada de la cavidad bucal mediante técnicas de microcirugía (99).

Otra técnica de injerto en bloque menos novedosa es la extracción de un injerto de la cresta ilíaca, y colocado en el lecho receptor de la cavidad bucal. Tras un período de seis meses de revascularización del bloque se colocan los implantes, que son cargados funcionalmente después de 4 meses de osteointegración (100).

Se han descrito múltiples zonas de donde obtener injertos óseos para efectuar aumentos del reborde alveolar, uno de ellos es la región mandibular, aunque tiene como principal inconveniente, en caso de la presencia de dientes en dicha región, el hecho de provocar un cambio en la sensibilidad locorregional, posiblemente debido al descenso en el aporte sanguíneo a los dientes cercanos a la zona donante (101).

Otra de las técnicas propuestas para la obtención de injertos, es utilizar un dispositivo piezoeléctrico que permite una osteotomía efectiva con una mínima hemorragia y traumatismo de los tejidos blandos, así como con una menor vibración y ruido en comparación con los instrumentos quirúrgicos convencionales, lo que reduce el estrés del paciente que se encuentra bajo anestesia local (102).

Otra forma de aumento óseo para facilitar la colocación de implantes en los pacientes con reabsorción ósea severa es la distracción osteogénica, ésta puede ser unidireccional o bidireccional, aunque solamente es efectiva cuando el aumento requerido es menor al $25 \%$ del hueso existente previamente, ya que en caso contrario es muy probable que exista la necesidad de hacer un injerto óseo posterior a la distracción osteogénica. De todos modos este tratamiento puede dar a lugar a inconvenientes y complicaciones, como defec- 
tos óseos del tipo dehiscencias o fenestraciones de los implantes y la incomodidad referida por el paciente, por lo que es indispensable para garantizar un mejor resultado, la absoluta colaboración del paciente o/y la de su familia (103-104).

Por otro lado existen alternativas a la práctica de técnicas complejas, que pueden ser efectivas en algunos casos y deben valorarse en la planificación de un tratamiento implantológico, como es el uso de los osteótomos para confeccionar el lecho de un implante. Tienen como objetivo, reducir el traumatismo y la destrucción ósea que produce el fresado, de forma que, en lugar de ser removido, el hueso es comprimido lateral y apicalmente consiguiendo una capa de hueso denso alrededor del implante. En términos de supervivencia esta técnica tiene resultados similares a la técnica convencional (105).

Una posibilidad terapéutica cada vez más utilizada para colocar implantes cuando no existe soporte óseo, es la colocación de éstos en la región pterigoidea del maxilar superior obviando así la necesidad de practicar una elevación del suelo del seno maxilar (106). Los implantes pterigoideos presentan una tasa de supervivencia del $94,7 \%$ de acuerdo con los resultados de la serie presentada por Sohn y cols. (102).

Respecto al empleo de membranas de barrera, para la prevención de la reabsorción del injerto óseo durante el periodo de curación, un artículo de revisión de Gielkens y cols. (107) concluye que esta técnica no está bien documentada en cuanto a sus resultados y que son necesarios más estudios para evaluar su eficacia.

Como hemos visto existen numerosas técnicas para el aumento óseo para facilitar la colocación de implantes en la cavidad bucal, pero para determinar cual de ellas es la más exitosa se precisan más estudios. Hay técnicas que se encuentran bien documentadas y con un éxito predecible a 5 años, como la elevación del seno maxilar o la regeneración ósea guiada, aunque en ambos casos debe precisarse que son técnicas muy sensibles y se requieren más estudios (108).

\section{PLASIMA RICO EN PLAQUETAS (PRP) Y FACTORES DE CRECIMIENTO}

La vascularización es un requisito fundamental para una correcta osteointegración de los implantes. Las plaquetas son las primeras células que aparecen en la herida quirúrgica. Estas células, además de iniciar la coagulación, son una importante fuente de factores de crecimiento y citoquinas, entre los que se encuentran: el factor de crecimiento insulínico l (IGF-1), factor de crecimiento derivado de las plaquetas (PDGF), factor de crecimiento transformador beta-1 y beta-2 (TGF- $\beta_{1}$ Y TGF- $\beta_{2}$ ), factor de crecimiento vascular endotelial (VEGF), factor de crecimiento celular endotelial derivado de las plaquetas (PDEGF), interleukina-l (IL-1), factor de crecimiento fibroblástico básico (bFGF) y el factor activador 4 de plaquetas (PAF-4). Cada uno de estos factores posee unas propiedades intrínsecas pero en general, todos estimulan la quimiotaxis, la proliferación celular y favorecen la angiogénesis.

El PDGF juega un importante papel en la curación de las heridas. Simion y cols. (109) utilizaron el factor de crecimiento derivado de las plaquetas recombinado humano (rhPDGF-BB) junto con un xenoinjerto de origen bovino en dos casos clínicos. En ambos casos consiguieron con éxito un aumento vertical y horizontal de la cresta alveolar para la posterior ubicación de implantes dentales. Mediante esta técnica evitan la morbilidad y la alta reabsorción a la que se asocia este tipo de injerto, sobre todo en aumentos verticales de la cresta ósea alveolar.

El PRP es un derivado de la sangre que se obtiene del propio paciente y que contiene una alta concentración de plaquetas. Un aumento de los factores de crecimiento en la herida quirúrgica debería dar lugar, en principio, a una aceleración en la curación de los tejidos duros y blandos pero en la literatura existe una gran controversia acerca de su efecto sobre la neoformación de hueso.

Los resultados obtenidos en diversos estudios muestran que el PRP acelera la curación de la herida favoreciendo la formación de hueso y tejidos blandos, sobre todo en las primeras fases de la cicatrización (110-112).

Torres y cols. (110) crearon 2 defectos craneales de 10 $\mathrm{mm}$ de diámetro en 12 conejos. Uno se rellenó con PRP y el otro no recibió ningún tipo de material. Los animales fueron sacrificados paulatinamente a las 2, 4, 6 y 8 semanas tras la intervención quirúrgica. Los resultados histológicos e histomorfométricos mostraron diferencias significativas en cuanto a la formación de hueso en favor del grupo de estudio, especialmente a las 4 semanas. A las 8 semanas la formación de hueso era similar en ambos grupos. Akça y cols. (11), en un estudio experimental realizado en tibias de conejo, colocaron un cilindro de titanio de 4 milímetros de diá- 
metro en cada tibia. Uno fue rellenado con PRP y el otro sin ningún tipo de material. 2 semanas después, se repitió la misma intervención y a las 6 semanas se sacrificaron los animales. Los cilindros se cortaron transversalmente por tres zonas, superior, media e inferior. Tanto en el grupo control como en el grupo de estudio se observó una mayor maduración ósea en el tercio inferior a las 6 y a las 8 semanas. A las seis semanas, en los cilindros del grupo control, el tejido fibroso era mayor en comparación a los de PRP, sobre todo en los tercios superiores. A las 8 semanas se observó que el tejido óseo se había igualado en los 2 grupos.

Lindeboom y cols. (112) midieron la densidad de la microvascularización capilar de la mucosa bucal en un estudio a boca partida sobre 20 elevaciones del seno maxilar en 10 pacientes. En ambos lados se injertó hueso particulado procedente de la cresta ilíaca, uno mezclado con PRP y otro no. Se colocó también un "onlay" procedente de la cresta ilíaca en cada zona intervenida. Se suturó la herida y el seno maxilar donde se había efectuado la mezcla, se aplicó y dejó reposar un gel de PRP en la mucosa durante un periodo de 15 minutos. En esta última área, se observó una aceleración significativamente mayor en la curación de la mucosa bucal durante los 10 primeros días, después de las dos semanas ya no habían diferencias significativas entre ambas.

La colocación de implantes inmediatos tras las exodoncias se asocia a menudo a un pequeño espacio residual entre la superficie del implante y el hueso llamado "gap". En estos espacios se pueden introducir células procedentes del tejido conectivo y del epitelio, impidiendo la correcta osteointegración de los implantes. Se ha propuesto la utilización del PRP sólo o combinado con otros materiales para impedir que esto suceda, favoreciendo así la neoformación de hueso alrededor de todo el implante. Se ha demostrado que otros materiales como el Bio-Oss ${ }^{\circledR}$ (Geistlich Pharma AG, Wolhusen, Suiza) y el adhesivo de fibrina enriquecido con plaquetas, estarían mas indicados para este propósito $(113,114)$.

Tae-Min y cols. (113) llevaron a cabo un estudio histomorfométrico en 6 perros. Se crearon "gaps" de 2 milímetros alrededor de cada uno de los 3 implantes colocados a cada perro. El "gap de uno de los implantes se rellenó con PRP, otro con adhesivo de fibrina enriquecido con plaquetas y en el último no se colocó ningún material. Los implantes a los que se les colocó PRP obtuvieron mayor superficie de contacto con el hueso que el grupo control, pero fue menor que aquellos "gaps" repletos de adhesivo de fibrina enriquecido con plaquetas $(10,2 \%<29,2 \%<59,7 \%)$.

Estos mismos autores hicieron otro estudio (114) muy parecido, pero el espacio fue rellenado con Bio-Oss ${ }^{\circledR}$ (Geistlich Pharma AG, Wolhusen, Suiza) y el otro con una mezcla de Bio-Oss ${ }^{\circledR}$ (Geistlich Pharma AG, Wolhusen, Suiza) y PRP. Se obtuvo un menor contacto hueso-implante en la mezcla $(30,8 \%)$ que sólo con el hueso de origen bovino $(60,1 \%)$.

También se ha propuesto el uso del PRP combinado con sulfato de calcio para evitar la reabsorción de la cresta alveolar que se produce tras una exodoncia. Este proceso se produce principalmente durante los tres primeros meses postexodoncia y conviene evitarlo o minimizarlo para alcanzar unos resultados funcionales y estéticos satisfactorios tras la ubicación de los implantes. En este estudio, Shi y cols. (115) extrajeron 4 dientes a 5 perros, 2 dientes anteriores y 2 posteriores. Uno de los dos alveolos anteriores postextracción se rellenó con una mezcla de sulfato de calcio y PRP, y el otro no se rellenó con ningún material. En los dos alveolos posteriores postextracción, en uno se volvió a colocar la mezcla de sulfato de calcio y PRP, y el último se rellenó sólo con sulfato de calcio. A las 8 semanas, no habían diferencias significativas en cuanto a la pérdida de hueso al comparar el lecho cubierto sólo con sulfato de calcio y el de la mezcla de sulfato de calcio con PRP. En cambio, se obtuvieron peores resultados en los alveolos donde no se había colocado material alguno.

\section{CIRUGÍA GUIADA Y CIRUGÍA SIN COLGAJO O MÍNIMAIMENTE INVASIVA}

La cirugía mínimamente invasiva o cirugía sin colgajo es una de las nuevas tendencias de la cirugía implantológica diseñada con el fin de mejorar el curso postoperatorio del paciente, reducir el tiempo quirúrgico, acelerar la cicatrización de los tejidos blandos e incrementar la satisfacción del paciente (116). Para poder aplicar esta opción es necesario que el paciente tenga una cantidad de hueso suficiente para prevenir posibles fenestraciones óseas del implante.

En un estudio reciente de Cannizaro y cols. (117), se observó que la colocación de implantes con carga inmediata en intervenciones sin colgajo daban un gran confort al paciente y un alto índice de éxito de los im- 
plantes. No obstante, esta técnica requiere mucha experiencia clínica y un gran conocimiento de la anatomía de la zona quirúrgica.

Jeong y cols. (118), obtuvieron como resultado en su estudio experimental en perros, que los implantes colocados con cirugía sin colgajo eran de mayor longitud y presentaban mayor superficie de contacto con el hueso $(70,4 \%)$, en comparación con los implantes colocados con colgajo ( $9 \mathrm{~mm}$ y $59,5 \%$ respectivamente).

Los criterios que deben seguirse para optar por la colocación de implantes con cirugía mínimamente invasiva son: una anchura ósea de $5 \mathrm{~mm}$, adecuada densidad del hueso alveolar y una cantidad de encía de al menos $4 \mathrm{~mm}$ desde el margen gingival libre a la unión mucogingival (119).

Por otro lado, la cirugía guiada representa un gran avance en el campo de la Implantología. La posibilidad de disponer de imágenes en tres dimensiones y planificar rehabilitaciones bucales con tanta precisión otorga una mayor seguridad al odontólogo y una mayor predictibilidad en sus tratamientos implantológicos.

Existen diferentes sistemas de cirugía implantológica guiada por la imagen, que son utilizados para la colocación de implantes en la cavidad oral o en otras áreas craneofaciales como remarcan Zhang y cols. (120), que con un nuevo sistema de diseño por ordenador planificaron la colocación de implantes en la región orbitaria. De esta manera se obtiene un mayor porcentaje de éxito y se evita dañar estructuras anatómicas sensibles, proporcionando ventajas estéticas y funcionales al contemplar las opciones rehabilitadoras.

Programas como el Simplant ${ }^{\circledR}$ (Dentegris, Düsseldof, Alemania) con su sistema SAFE (Secure, Acurate, Flexible, and Ergonomic System) permiten la colocación exacta de los implantes basándose casi exclusivamente en el plan protésico. Además facilita una cirugía simple, controlada, segura y mínimamente invasiva, obteniendo un curso postoperatorio más favorable (121).

Para incrementar la precisión de la tomografía computadorizada (TC) en cirugía implantológica guiada, Rebaudi (122) propone el uso del Ray Set ${ }^{\circledR}$ (Biaggini Medical Devices, Génova, Italia), con el que ya ha probado su gran eficacia y utilidad en la planificación de tratamientos ortodóncicos. Se trata de un aparato que combina los datos del TC y los de un articulador semi- ajustable para la colocación exacta de los implantes, ofreciendo la posibilidad de crear una prótesis implantosoportada definitiva que podrá ser colocada de forma inmediata después de la cirugía.

\section{ORTODONCIA Y MINIIMPLANTES}

El primer minitornillo fue introducido en la práctica odontológica por Kanomi en 1997. En la actualidad, los minitornillos están siendo de gran utilidad y son ampliamente utilizados en Ortodoncia como dispositivos de anclaje temporal. Debido a sus características y prestaciones se han modificado los planes de tratamiento ortodóncico clásicos. Como por ejemplo el caso que plantean Choi y cols. (123) con el uso de minitornillos como anclaje para corregir una clase II con protrusión del labio superior y apiñamiento severo. Clásicamente se podrían plantear 2 planes terapéuticos: la cirugía ortognática o el tratamiento ortodóncico de enmascaramiento. La tercera opción sería la propuesta por estos autores que exigiría la distalización de los primeros molares superiores mediante el uso de minitornillos. A los 5 meses consiguen distalizar los primeros molares superiores $4 \mathrm{~mm}$ y a los 8 meses $8 \mathrm{~mm}$.

Dentro de las ventajas del uso de minitornillos cabe destacar el mínimo procedimiento quirúrgico que requieren, sus amplias indicaciones, su pequeña dimensión, la gran posibilidad de colocación en muchas regiones intraorales y que no se requiere la colaboración del paciente (124).

En el mercado existen distintos sistemas de minitornillos ortodóncicos. Por ello Lin y cols. (124) efectuaron un estudio comparativo de éstos, analizando las características de cada uno de ellos, con el objetivo de determinar el diseño ideal que debería tener un minitornillo. Éste tiene que estar fabricado de un material biocompatible capaz de soportar varias magnitudes y direcciones de fuerzas ortodóncicas sin sufrir fatiga ni riesgo de fractura. Los minitornillos son de titanio puro o de una aleación de titanio $\left(\mathrm{Ti}_{6} \mathrm{Al}_{4} \mathrm{~V}\right)$. Esta aleación proporciona un mayor grado de dureza y tiene la ventaja de que no se necesita pasar una fresa antes de su colocación en hueso duro. Otras condiciones que debería de cumplir es que se pudiera cargar inmediatamente después de su inserción, su estabilidad primaria debería de mantenerse hasta su remoción y el diseño de su cabeza tendría que ser compatible con todos los accesorios ortodóncicos existentes. Además, el procedimiento quirúrgico de su inserción tiene que ser simple, eficaz y efectivo. 
El diseño de la plataforma del minitornillo debería evitar la irritación de los tejidos gingivales cercanos. Tiene que ser lisa y pulida y de un grosor de 1 a 2 milímetros mayor que el grosor de los tejidos blandos del lugar de inserción del minitornillo. Estudios demuestran que los sistemas de anclaje esqueléticos ya sean miniplacas de titanio, minitornillos o implantes dentales desarrollan un 10\% de respuestas inflamatorias agudas durante el tratamiento ortodóncico y, en el peor de los casos, se debe remover la placa de anclaje. Sato y cols. (125) llevaron a cabo un estudio para comparar el perfil de la flora bacteriana en el surco gingival de alrededor de las placas de titanio de anclaje ortodóncico frente al perfil del surco gingival. Para ello recogieron muestras de líquido crevicular del interior de los surcos gingivales de alrededor de la placa de anclaje de 7 pacientes sin inflamación, de 3 con inflamación alrededor de ésta y finalmente de surcos gingivales de 7 pacientes con buena salud periodontal. Se analizaron y se compararon. Se aislaron 184 cepas en los surcos sin inflamación de alrededor de la placa de anclaje, de las cuales un $59 \%$ se trataba de bacterias anaeróbicas y un $40 \%$ facultativas. Predominaron las bacterias Gram negativo: Campylobacter (12\%), Fusobacterium (10\%) y Selenomonas (10\%), y las Gram positivo facultativas: Actinomyces (17\%) y Streptococcus $(8,2 \%)$. De los surcos con inflamación alrededor de la placa de anclaje encontraron que un $83 \%$ eran bacterias anaeróbicas y que predominaron las Gram negativo como la Prevotella (47\%), Fusobacterium (33\%), y Campylobacter (16\%). Finalmente, en los surcos gingivales de los dientes sanos hallaron un $67 \%$ de bacterias facultativas Gram positivo como Actinomyces (37\%) y Streptococcus (20\%) y un $31 \%$ de bacterias anaerobias. Los resultados de este estudio sugieren que el ambiente del surco alrededor de la placa de anclaje de titanio es anaeróbico, por lo que existe un predominio de bacterias anaeróbicas que pueden desencadenar procesos infecciosos. Por este motivo es necesario seguir un control de placa estricto por parte del paciente y del profesional para prevenir posibles problemas infecciosos.

La longitud de los minitornillos que podemos encontrar en el mercado van de 4 a $12 \mathrm{~mm}$. Lo ideal sería elegir la más larga posible sin poner en riesgo estructuras anatómicas como son las raíces de los dientes vecinos, vasos o nervios, etc. Por lo que se refiere a la elección del diámetro del minitornillo, se puede escoger de 1 a 2,3 $\mathrm{mm}$ dependiendo del lugar donde se quiera insertar. Los de diámetro más pequeño están indicados en los casos que se tengan que colocar entre dientes.
El diámetro, la longitud y el diseño del minitornillo juegan un papel muy importante en su retención. Song y cols. (126) evaluaron las características mecánicas de tres 3 tipos de minitornillos autorroscantes (uno cilíndrico y 2 cónicos). Para ello emplearon bloques de hueso artificial con diferentes grosores de hueso de tipo cortical (1, 1,5 y $2 \mathrm{~mm}$ ) para lograr una densidad ósea homogénea evitando cualquier posible sesgo. Midieron el torque, el tiempo de inserción y de remoción. El grosor de la cortical de hueso influye en el torque de inserción dependiendo del minitornillo que se emplea. El minitornillo cónico con un diámetro creciente hacia coronal es el diseño que logró tener mayor torque de inserción. El torque de inserción y de remoción en grosores de cortical de 1 a $2 \mathrm{~mm}$ no se incrementa si se emplea un minitornillo cilíndrico, en cambio si que se produce un aumento significativo si se utilizan minitornillos cónicos. Así pues, recomiendan el uso de minitornillos cónicos cuando el paciente tiene una cortical gruesa.

El uso de minitornillos, en algunos casos, no será suficiente para conseguir el anclaje necesario para llevar a cabo un correcto plan de tratamiento ortodóncico. Mauro y cols. (127) reportan un estudio preliminar acerca de la utilización de implantes dentales convencionales colocados en el paladar como anclaje ortodóncico temporal. Se trata de una buena alternativa en pacientes que están en crecimiento y que presentan una clase II con hiperplasia del maxilar superior, cuando el anclaje dental no es suficiente; o bien en pacientes con clase III con hipoplasia del maxilar superior con un gran apiñamiento, donde las extracciones se tienen que evitar para mantener un perfil estético aceptable. En pacientes adultos, las indicaciones serían: casos donde el anclaje en el maxilar superior es insuficiente y en pacientes con oligodoncia o displasia ectodérmica. La zona media del paladar duro es la que se considera que tiene mayor anclaje pero no se acaba de osificar del todo hasta aproximadamente los 23 años, además, se caracteriza por tener poco grosor de hueso. Una buena alternativa a esta localización, sería la zona que está situada a unos 6-9 mm posteriores al agujero nasopalatino y a 3-6 $\mathrm{mm}$ de la línea media ya que existe más volumen de hueso. Se recomienda usar implantes cortos para prevenir la perforación de las fosas nasales y la lesión de las raíces vecinas. Estos autores proponen un estudio preliminar en 4 pacientes: 2 niños, un adulto joven y un adulto. Las fuerzas ortodóncicas se iniciaron a los tres meses de la colocación de los implantes palatinos en 3 casos y a los 8 meses en un caso. Estuvieron ejerciendo función durante 1 año, pero no se retiraron in- 
mediatamente tras finalizar el tratamiento ortodóncico por si a caso existía algún tipo de recidiva. Resaltan la utilidad de los implantes cortos para tratar maloclusiones severas con ortodoncia, aunque faltan estudios prospectivos que evalúen la eficacia y las ventajas de esta indicación.

El uso de miniimplantes no sólo es útil para casos de ortodoncia sino que también pueden indicarse para rehabilitar zonas edéntulas con una reabsorción ósea severa. En una revisión bibliográfica sobre miniimplantes, Morand y Irinakis (128) concluyen que está justificado el uso de miniimplantes incluso en la zona posterior del maxilar superior y que es una opción que debemos tener en cuenta para ofrecerla a los pacientes. Aunque las opiniones no son unánimes, muchos estudios confirman que estos implantes pueden ser predecibles y tener tasas de éxito iguales a los implantes más largos.

Con respecto a la unión implante-hueso en los pacientes con carga ortodóncica, Cattaneo y cols. (129) hicieron un estudio minucioso para describir los efectos del estrés y la tensión en la respuesta biológica del hueso situado alrededor de un implante que recibe fuerzas ortodóncicas. Este estudio se efectuó en animales de experimentación (4 monos Macaca fascicularis). Se practicaron las exodoncias de todos los segundos premolares y primeros molares, esperando 20 semanas para obtener la curación y hacer la posterior colocación de los implantes. A las 17 semanas se cargaron los implantes con fuerzas ortodóncicas de $50 \mathrm{cN}$. Para analizar los cambios dinámicos del hueso situado alrededor de los implantes se les administró intravenosamente marcadores específicos. A las 16 semanas de carga se practicó la eutanasia, para obtener las muestras para el estudio. Las muestras fueron valoradas mediante tomografías microcomputarizadas con posterior reconstrucción en 3D, y efectuaron los análisis histomorfométricos. Integraron todos los resultados obtenidos para evaluar la remodelación del hueso situado alrededor de estos implantes. Tras este estudio encuentran los siguientes hallazgos clínicos: las magnitudes de fuerzas ortodóncicas son pequeñas en comparación a las cargas funcionales, por este motivo, juegan un papel menor en las reacciones óseas alrededor de los implantes. La carga ortodóncica se tolera correctamente cuando se aplica después de un periodo de tiempo apropiado, y finalmente, la reacción individual y las diferencias anatómicas del lugar de inserción son los factores principales en la reacción de los tejidos adyacentes al implante.

\section{AGRADECIMIENTOS}

Este estudio ha sido realizado por el grupo de investigación "Patología y Terapéutica Odontológica y Maxilofacial" del Instituto UB-IDIBELL con el soporte económico del convenio docente-asistencial de Cirugía Bucal entre la Universitat de Barcelona, el Consorci Sanitari Integral y al Servei Català de la Salut de la Generalitat de Catalunya.

\section{BIBLIOGRAFÍA}

1. Iacono V, Cochran D. State of the science on implant dentistry: A workshop developed using an evidencebased approach. Int J Oral Maxillofac Implants 2007; 22:7-10.

2. Proskin H, Jeffcoat R, Catlin A, Campbell J, Joffcoat M.A meta-analytic approach to determine the state of the science on implant dentistry. Int J Oral Maxillofac Implants 2007; 22:11-8.

3. Faraco FN, Kawakami PY, Mestnik MJ, Ferrari DS, Shibli JA. Effect of anesthetics containing lidocaine and epinephrine on cardiovascular changes during dental implant surgery. J Oral Implantol 2007; 33:84-8.

4. Mazzocchi A, Passi L, Moretti R. Retrospective analysis of 736 implants inserted without antibiotic therapy.J Oral Maxillofac Surg 2007; 65:2321-3.

5. Dearo de Morais J, Sakakura CE, Castro Monteiro LL, Scaf G. A survey of radiographic measurment estimation in assessment of dental implant length. J Oral Implantol 2007; 23:186-9.

6. Kullman L, Asfour A, Zetterqvist L, Andersson L. Comparison of radiographic bone height assessment in panoramic and intraoral radiographs of implant patients. Int J Oral Maxillofac Implants 2007; 22:96-100.

7. Tolstunov L. Implant zones of the jaws: Implant location and related success rate. J Oral Implantol 2007; 23:21 120.

8. Tolstunov L. Combynation syndrome: Classification and case report. J Oral Implantol 2007; 33:139-51.

9. Blahout R, Hienz S, Solar P, Matejka M, Ulm C. Quantification of bone resorption in the infterforaminal region of the atrophic mandible. Int J Oral Maxillofac Implants 2007; 22:609-15. 
10. Devlin H, Horner K. A study to assess the relative influence of age and edentulous upon mandibular bone mineral density in the female subjects. Oral Surg Oral Med Oral Pathol Oral Radiol Endod 2007; 104:117-21.

11. Parker S. Surgical laser use in implantology and endodontics. Br Dent J 2007; 202:377-86.

12. Ohyama H, Nagai S, Tokutomi H, Ferguson M. Recreating an esthetic smile: A multidisciplirnary approach. Int J Periodontics Restorative Dent 2007; 27:61-9.

13. Jivraj S, Corrado P, Chee W. An interdisciplinary approach to treatment planning in implant dentistry. $\mathrm{Br}$ Dent J 2007; 202:11-7.

14. Horwitz J, Zuabi O, Peled M, Machtei EE. Immediate and delayed restoration of dental implants in periodontally susceptible patients: 1-year results. Int J Oral Maxillofac Implants. 2007; 22:423-9.

15. Hoffmann O, Beaumont C, Zafiropoulos GG. Combined periodontal and implant treatment of a case of aggressive periodontitis. J Oral Implantol. 2007; 33:288-92.

16. Park JB. Bone healing at a failed implant site in a type II diabetic patient: clinical and histologic evaluations: $A$ case report. J Oral Implantol 2007; 33:28-32.

17. Erdogan O, Shafer DM, Taxel P, Freilich MA. A review of the association between osteoporosis and alveolar ridge augmentation. Oral Surg Oral Med Oral Pathol Oral Radiol Endod. 2007; 104:738-13.

18. Colella G, Cannavale R, Pentenero M, Gandolfo S. Oral implants in radiated patients: A systematic review. Int J Oral Maxillofac Implants 2007; 22:616-22.

19. Prabhu N, Duckmanton N, Stevenson AR, Cameron A. The placement of osseointegrated dental implants in a patient with type IV B osteogenesis imperfecta: A 9-year follow-up. Oral Surg Oral Med Oral Pathol Oral Radiol Endod 2007; 103:349-54.

20. Penarrocha M, Larrazabal C, Balaguer J, Serrano C, Silvestre J, Bagan JV. Restoration with implants in patients with recessive dystrophic epidermolysis bullosa and patient satisfaction with the implant-supported superstructure. Int J Oral Maxillofac Implants 2007; 22:651-5.

21. Kramer FJ, Baethge C, Tschernitschek H. Implants in children with ectodermal dysplasia: A case report and literature review. Clin Oral Implants Res 2007;18:140-6.
22. Grassi S, Piatelli A, Ferrari DS, Figueiredo LC, Feres M, Iezzi $G$ y cols. Histologic evaluation of human bone integration on machined and sandblasted acid-etched titanium surfaces in type IV bone. J Oral Implantol 2007;33:8-12.

23. Vallecillo Capilla M, Romero Olid N, Olmedo Gaya MV, Reyes Botella C, Zorrilla Romera C. Cylindrical dental implants with hydroxyapatite- and titanium plasma spray-coated surfaces: 5-year results. J Oral Implantol 2007;33:59-68.

24. Park JW, Lee SG, Choi BJ, Suh JY. Effects of a cell adhesion molecule coating on the blasted surface of titanium implants on bone healing in the rabbit femur. Int J Oral Maxillofac Implants 2007; 22:533-41.

25. Goené RJ, Testori T, Trisi P. Influence of a nanometer-scale surface enhancement on de novo bone formation on titanium implants: A histomorphometric study in human maxillae. Int J Periodontics Restorative Dent 2007;27:21 1-9.

26. Protivínský J, Appleford M, Strnad J, Helebrant A, Ong JL. Effect of chemically modified titanium surfaces on protein adsorption and osteoblast precursor cell behaviour. Int J Oral Maxillofac Implants 2007;22:542-50.

27. Shibli JA, Vitussi TR, García RV, Zenóbio EG, Ota-Tsuzuki C, Cassoni A y cols Implant surface analysis and microbiologic evaluation of failed implants retrieved from smokers. J Oral Implantol 2007; 33:232-8.

28. Juodzbalys G, Saprogoniene M, Wennerberg A, Baltrukonis T. Titanium dental implant surface micromorphology optimization. J Oral Implantol 2007;33:177-85.

29. McAllister BS. Scalloped implant designs enhance interproximal bone levels. Int J Periodontics Restorative Dent 2007;27:9-15.

30. Froum SJ, Cho SC, Cho YS, Elian N, Tarnow D. Narrowdiameter implants: A restorative option for limited interdental space. Int J Periodontics Restorative Dent 2007; 27:449-55.

31. Finne K, Rompen E, Toljanic J. Clinical evaluation of a prospective multicenter study on 1-piece implants. Part 1: Marginal bone level evaluation after 1 year of followup. Int J Oral Maxillofac Implants 2007;22:226-34.

32. Pedroza JE, Torrealba Y, Elias A, Psoter W. Comparison of the compressive strength of 3 different implant design systems. J Oral Implantol 2007;33:1-7. 
33. Georgiopoulos B, Kalioras K, Provatidis C, Manda M, Koidis P. The effects of implant length and diameter prior to and after osseointegration: A 2-D finite element analysis. J Oral Implantol 2007; 33:243-56.

34. Bornstein MM, Harnisch H, Lussi A, Buser D. Clinical performance of wide-body implants with a sandblasted and acid-etched (SLA) surface: Results of a 3-year follow-up study in a referral clinic. Int J Oral Maxillofac Implants 2007; 22:631-8.

35. Huang HL, Chang CH, Hsu JT, Fallgatter AM, Ko CC. Comparison of implant body designs and threaded designs of dental implants: A 3-dimensional finite element análisis. Int J Oral Maxillofac Implants 2007; 22:551-62.

36. Bächle M, Butz F, Hübner U, Bakalinis E, Kohal RJ. Behavior of CAL72 osteoblast-like cells cultured on zirconia ceramics with different surface topographies. Clin Oral Implants Res 2007; 18:53-9.

37. Oliva J, Oliva X, Oliva JD. One-year follow-up of first consecutive 100 zirconia dental implants in humans: $A$ comparison of 2 different rough surfaces. Int J Oral Maxillofac Implants 2007; 22:430-5.

38. Gallucci GO, Mavropoulos A, Bernard JP, Belser UC. Influence of immediate implant loading on peri-implant soft tissue morphology in the edentulous maxilla. Int J Oral Maxillofac Implants 2007; 22:595-602.

39. Peñarrocha-Diago M, Gómez-Adrián MD, BalaguerMartínez J, García-Mira B. Mandibular connective tissue pedicle flaps in implant dentistry: Report of three cases. J Oral Implantol 2007; 33:127-32.

40. De Castro LA, Vencio EF, Mendonca EF. Epithelial inclusion cyst after free gingival graft: A case report. Int J Periodontics Restorative Dent 2007; 27:465-9.

41. Parker S. Surgical laser use in implantology and endodontics. Br Dent J 2007; 202:377-86.

42. Funato A, Salama MA, Ishiwaka T, Garber DA, Salama H. Timing, Positioning, and Sequential Staging in Esthetic Implant Therapy: A four-dimensional perspective. Int J Periodontics Restorative Dent 2007; 27:313-23.

43. Cardaropoli D, Debernardi C, Cardaropoli G. Immediate placement of implant into impacted maxillary canine extraction socket. In J Periodontics Restorative Dent 2007; 27:71-7.
44. Quirynen M, Van Assche N, Daniele B, Berglundh. How does the timing of implant placement to extraccion affect outcome. Int J Oral Maxillofac Implants 2007; 22 : 203-23.

45. Orenstein IH, MacDonald DE, Tao AC, Morris HF. Electronic percussive testing of the stability of an immediate provisionalized implant placed into a fresh extraction socket: A pilot evaluation. J Oral Implant 2007; 33:69-74.

46. Casap N, Zeltser C, Wexler A, Tarazi E, Zeltser R. Immediate placement of dental implants into debrided infected dentoalveolar sockets. Int J Oral Maxillofac Surgery 2007; 65:384-92.

47. De Smet E, Duyck J, Vander Sloten J, Jacobs R, Naert I. Timing of loading: inmediate, early or delayed in the outcome of implants in the edentulous mandible: $\mathrm{A}$ prospective clinical trial. Int J Oral Maxillofac Implants 2007 ; $22: 580-94$.

48. Longoni S, Sartori M, Apruzzese D, Davide R, Baldoni M. Immediate loading: A simple protocol to create a passively fitting provisional fixed implant-supported complete denture in 1 day. Int J Periodontics Restorative Dent 2007; 27:370-7.

49. Hahn JA. Clinical and radiographic evaluation of onepiece implants used for immediate function. J Oral Implantol 2007; 33:152-5.

50. Noelken R, Morbach T, Kunkel M, Wagner W. Inmediate function with NobelPerfect implants in the anterior dental arch. Int J Periodontics Restorative Dent 2007;27: 277-85.

51. Davarpanah M, Caraman M, Jakubowicz-Kohen B, KebirQuelin M, Szmukler-Moncler S. Prosthetic success with a maxillary immediate-loading protocol in the multiplerisk patient. Int J Periodontics Restorative Dent 2007; 27:161-9.

52. Shiigai T. Pilot study in the identification of stability values for determining inmediate and early loading of implants. J Oral Implantol 2007; 33:13-21.

53. Schincaglia GP, Marzola R, Scapoli CH, Scotti R. Immediate loading of dental implants supporting fixed partial dentures in the posterior mandible: A randomized controlled split-mouth study-machined versus titanium oxide implant surface. Int J Oral Maxillofac Implants $2007 ; 22: 35-46$. 
54. Oliveira R, Novaes A, Taba M, De Souza S, Papalexiou V. The Effect of bone condensation and crestal preparation on the bone response to implants designed for immediate loading: A histomorphometric study in dogs. Int J Oral Maxillofac Implants 2007; 22:63-71.

55. Balshi SF, Wolfinger GF, Balshi TJ. An examination of immediately loaded dental implant stability in the diabetic patient using resonance frequency analysis (RFA). Quintessence Int 2007; 38:271-9.

56. Akça K, Akkocauglu M, Cömert A, Tekdemir I, Çehreli MC. Bone strains around immediately loaded implants supporting mandibular overdentures in human cadavers. Int J Oral Maxillofac Implants 2007; 22:101-9.

57. Chiapasco M, Gatti C, Gatti F. Immediate loading of dental implants placed in severely resorbed edentulous mandibles reconstructed with autogenous calvarial grafts. Clin Oral Impl Res 2007;18:13-20.

58. Degidi M, Piatelly A, Iezzi G. Immediately loaded short implants: Analysis of a case series of 133 implants. Quintessence Int 2007;38:193-201.

59. Lambrecht JT, Hodel I. Long-term results of immediately loaded interforaminal implants. Quintessence Int 2007; 38:111-9.

60. Degidi M, Piatelly A, Iezzi G. Retrospective study of 200 immediately loaded implants retaining 50 mandibular overdentures. Quintessence Int 2007;38:281-8.

61. Jokstad A, Carr AB. What Is the effect on outcomes of time-to-loading of a fixed or removable prosthesis placed on implant(s)?. Int J Oral Maxillofac Implants 2007;22:19-48.

62. Tözüm TF, Türkyilmaz I, Yamalik N, Tümer C, Kilinç A, Kilinç K, et al. The Effect of delayed versus early loading on nitric oxide metabolism around dental implants: An 18-month comparative follow-up study. J Oral Maxillofac Implants 2007;22:53-62.

63. Mardinger O, Manor Y, Mijiritsky E, Hirshberg A. Lingual perimandibular vessels associated with lifethreatening bleeding: An anatomic study. Int J Oral Maxillofac Implants. 2007;22:127-31.

64. El-Naaj A, Trost O, Tagger-Green N, Trouilloud P, Robe $\mathrm{N}$, Malka G, et al. Péri-implantite ou carcinome épidermoide? Rev Stomatol Chir Maxillofac. 2007;108:45860.
65. Chee W, Jivraj S. Failures in implant dentistry. Br Dent J. 2007;202:123-9.

66. Balshi SF,Wolfinger GJ, Balshi TJ. A retrospective evaluation of a treatment protocol for dental implant periapical lesions: Long-term results of 39 implant apicoectomies. Int J Oral Maxillofac Implants. 2007; 22:267-72.

67. Chung DM, Oh TJ, Lee J, Misch CE, Wang HL. Factors affecting late implant bone loss: A retrospective analysis. Int J Oral Maxillofac Implants. 2007;22:117-26.

68. Liskmann S, Vihalemm T, Salum O, Zilmer K, Fischer K, Zilmer M. Characterization of the antioxidant profile of human saliva in peri-implant health and disease. Clin Oral Impl Res. 2007; 18:27-33.

69. Takasaki AA, Aoki A, Mizutani K, Kikuchi S, Oda S, Ishikawa I. Er:YAG laser therapy for peri-implant infection: A histological study. Lasers Med Sci. 2007; 22:143-57.

70. Deppe H, Horch HH, Neff A. Conventional versus CO2 laser-assisted treatment of peri-implant defects with the concomitant use of pure-phase b-tricalcium phosphate: A 5-year clinical report. Int J Oral Maxillofac Implants. 2007;22:79-86.

71. Sennhenn-Kirchner S, Klaue S, Wolff N, Mergeryan H, Zepelin MBv, Jacobs HG. Decontamination of rough titanium surfaces with diode lasers: Microbiological findings on in vivo grown biofilms. Clin Oral Impl Res. 2007;18:126-32.

72. You TM, Choi BH, Zhu SJ, Jung JH, Lee SH, Huh JY, et al. Treatment of experimental peri-implantitis using autogenous bone grafts and platelet-enriched fibrin glue in dogs. Oral Surg Oral Med Oral Pathol Oral Radiol Endod. 2007;103:34-7.

73. Pongnarisorn NJ, Gemmell E, Tan AE, Henry PJ, Marshall RI, Seymour GJ. Inflammation associated with implants with different surface types. Clin Oral Impl Res. 2007; 18:114-25.

74. Nakajima Y, Fiorellini JP, Kim DM, Weber HP. Regeneration of standardized mandibular bone defect using expanded polytetrafluoroethylene membrane and various bone fillers. Int J Periodontics Restorative Dent 2007; 27:151-9.

75. Fiorellini JP, Kim DM, Nakajima Y, Weber HP. Osseointegration of titanium implants following guided 
bone regeneration using expanded polytetrafluoroethylene membrane and various bone fillers. Int J Periodontics Restorative Dent 2007; 27:287-94.

76. Simion M, Dahlin C, Rocchietta I, Stavropoulos A, Sanchez R, Karring T. Vertical ridge augmentation with guided bone regeneration in association with dental implants: An experimental study in dogs. Clin Oral Impl Res 2007;18: 86-94.

77. Merli M, Migani M, Esposito M. Vertical ridge augmentation with autogenous bone grafts: resorbable barriers supported by ostheosynthesis plates versus titanium-reinforced barriers. A preliminary report of a blinded, randomized controlled clinical trial. Int J Oral Maxillofac Implants 2007;22: 373-82.

78. Bilir A, Aybar B, Tanrikulu SH, Issever H, Tuna S. Biocompatibility of different barrier membranes in cultures of human CRL 11372 osteoblast-like cells: An immunohistological study. Clin Oral Impl Res 2007; 18:46-52.

79. Kfir E, Kfir V, Eliav E, Kaluski E. Minimally invasive guided bone regeneration. J Oral Implant 2007;23: 205-10.

80. Kfir E, Kfir V, Kaluski E. Immediate bone augmentation after infected tooth extraction using titanium membranes. J Oral Implant 2007;23:133-8.

81. Coradazzi LF, Garcia Jr IR, Manfrin TM. Evaluation of autogenous bone grafts, particulate or collected during osteotomy with implants burs: Histologic and histomorphometric analysis in rabbits. Int J Oral Maxillofac Implants 2007;22:201-7.

82. Anitua E, Carda C, Andia I. A novel drilling procedure and subsequent bone autograft preparation: $A$ technical note. Int J Oral Maxillofac Implants 2007;22:138-45.

83. Etcheson AW, Miley D, Gillespie J. Osseous coagulum collected in bone traps: Potential for bacterial contamination and methods for decontamination. J Oral Implant 2007;23:109-15.

84. Irinakis T, Tabesh M. Preserving the socket dimensions with bone grafting in single sites: An esthetic surgical approach when planning delayed implant placement. J Oral Implant 2007;23:156-63.

85. Ito K, Minegishi T, Takayama T, Tamura T, Yamada Y, Sato S. Effects of ipriflavone on augmented bone using a guided bone regeneration procedure. Clin Oral Impl Res 2007;18: 60-8.

86. Luczyszyn SM, Grisi MFM, Novaes Jr A, Palioto DB, Souza SLS, Taba Jr M. Histologic analysis of the acellular dermal matrix graft incorporation process: A pilot study in dogs. Int J Periodontics Restorative Dent 2007;27:341-7.

87. Marchetti C, Pieri F, Trasarti S, Corinaldesi G, Degidi M. Impact of implant surface and grafting protocol on clinical outcomes of endosseous implants. Int J Oral Maxillofac Implants 2007;22:399-407.

88. Wallace SS, Mazor Z, Froum SJ, Cho SC, Tarnow DP. Schneiderian membrane perforation rate during sinus elevation using piezosurgery:Clinical results of consecutive cases. Int J Periodontics Restorative Dent. 2007;27:413-9.

89. Becktor JP, Isaksson S, Sennerby L. Endosseous implants and bone augmentation in the partially dentate maxilla: An analysis of 17 patients with a follow-up of 29 to 101 months. Int J Oral Maxillofac Implants 2007;22:603-8.

90. Lee SH, Choi BH, Li J, Jeong SM, Kim HS, Ko CY. Comparison of corticocancellous block and particulate bone grafts in maxillary sinus floor augmentation for bone healing around dental implants. Oral Surg Oral Med Oral Pathol Oral Radiol Endod 2007;104:324-8.

91. Zizelmann C, Schoen R, Metzger MC, Schmelzeisen R, Schramm A, Dott B, et al. Bone formation after sinus augmentation with engineered bone. Clin Oral Implants Res. 2007;18:69-73.

92. Crespi R, Vinci R, Cappare P, Gherlone E, Romanos GE. Calvarial versus iliac crest for autologous bone graft material for a sinus lift procedure: A histomorphometric study. Int J Oral Maxillofac Implants 2007;22:527-32.

93. Schlegel KA, Zimmermann R, Thorwarth M, Neukam FW, Klongnoi B, Nkenke E, et al. Sinus floor elevation using autogenous bone or bone substitute combined with platelet-rich plasma. Oral Surg Oral Med Oral Pathol Oral Radiol Endod 2007;104:15-25.

94. Lee HJ, Choi BH, Jung JH, Zhu SJ, Lee SH, Huh JY, et al. Maxillary sinus floor augmentation using autogenous bone grafts and platelet-enriched fibrin glue with simultaneous implant placement. Oral Surg Oral Med Oral Pathol Oral Radiol Endod. 2007;103:329-33.

95. Iezzi G, Fiera E, Scarano A, Pecora G, Piattelli A. Histologic evaluation of a provisional implant retrieved 
from man 7 months after placement in a sinus augmented with calcium sulphate: A case report. J Oral Implantol. 2007; 33:89-95.

96. Li XJ. Different osteogenic pathways between rhBMP2/ACS and autogenous bone graft in 190 maxillary sinus floor augmentation surgeries. J Oral Maxillofac Surg 2007;65:36-42.

97. Stavropoulos A, Karring T, Kostopoulos L. Fully vs. partially rough implants in maxillary sinus floor augmentation: A randomized-controlled clinical trial. Clin Oral Implants Res 2007; 18:95-102.

98. Shibli JA, Faveri M, Ferrari DS, Melo L, Garcia RV, d'Avila $\mathrm{S}$, et al. Prevalence of maxillary sinus septa in 1024 subjects with edentulous upper jaws: A retrospective study. J Oral Implantol 2007; 33:293-6.

99. Cannizaro G, Leone M, Consolo U, Ferri V, Licitra G, Worthington H, Esposito M. Augmentation of the posterior atrophic edentulous maxilla with implants placed in the ulna: A prospective single-blind controlled clinical trial. Int J Oral Maxillofac Implants 2007; 22 : 280-8.

100. Güven O. Rehabilitation of severely atrophied mandible using free iliac crest bone grafts and dental implants: Report of two cases. J Oral Implant 2007;33:122-6.

101. Von Arx T, Chappuis V, Winzap KC, Borntein M. Laser doppler Flowmetry for assessment of anterior mandibular teeth in conjuction with bone harvesting in the simphysis: A clinical pilot study. Int J Oral Maxillofac Implants 2007;22:383-9.

102. Sohn D, Ahn M, Lee W, Yeo D, Lim S. Piezolectric osteotomy for intraoral harvesting of bone blocks. Int J Periodontics Restorative Dent 2007;27:127-31.

103. Schleier P,Wolf C, Siebert H, Shafer D, Freilich M, Berndt A, Schuman D. Treatment options in distraction osteogenesis therapy using a new bidirectional distractor system. Int J Oral Maxillofac Implants 2007;22: 408-16.

104. Saulacic N, Somoza M, Gandara P, García A. Bone defect formation during implant placement following alveolar distraction. Int J Oral Maxillofac Implants 2007; 22 : 47-52.

105. Shalabi MM, Manders P, Mulder J, Jansen J, Creugers N. A meta-analysis of clinical studies to estimate the 4.5-year survival rate of implants placed with the osteotome technique. Int J Oral Maxilofac Implants 2007;22: 110-7.

106. Fernández J, Valeron P. Long-term results in placement of screw-type implants in the pterygomaxillarypyramidal region. Int J Oral Maxillofac Implants 2007; 22:195-200.

107. Gielkens P, Bos R, Raghoebar G, Stegenga B. Is there evidence that barrier membranes prevent bone resorption in autologous bone grafts during the healing period? A sistematic review. Int J Oral Maxillofac Implants 2007;22:390-8.

108. Aghaloo T, Moy P. Wich hard tissue augmentation techniques are the most succesful in furnishing bony support for implant placement?. Int J Oral Maxillofac Implants 2007;22:49-70.

109. Simion M, Rocchietta I, Dellavia C. Three-dimensional ridge augmentation with xenograft and recombinant human plateled-derived growth factor-bb in humans: Report of two cases. Int J Periodontics Restorative Dent 2007;27:109-15.

110. Torres J, Tresguerres I, Tamimi F, Clemente C, Niembro $\mathrm{E}, \mathrm{Blanco} \mathrm{L}$. Influence of platelet-rich plasma on bone regeneration: A histomorphometric study in rabbit calvaria. Int J Oral Maxillofac Implants 2007;22:563-8.

111. Akça K, Demiralp B, Dagdeviren A. Plateled-rich plasma and bone healing: A histologic study in titanium bone chambers. Int J Periodontics Restorative Dent 2007; 27:387-92.

112. Lindeboom JAH, Mathura KR, Aartman IHA, Kroon FHM, Milstein DMJ, Ince C. Influence of the application of plateled-enriched plasma in oral mucosa wound healing. Clin Oral Impl Res 2007;18:133-9.

113. Tae-Min Y, Byung-Ho CH, Shi-Jiang Z, Seoung-Ho L, JinYoung $\mathrm{H}$, Hyun-Jung $\mathrm{L}$, et al. Platelet-enriched fibrin glue and platelet-rich plasma in the repair of bone defects adjacent to titanium dental implants. Int J Oral Maxillofac Implants 2007;22:417-22.

1 14. Tae-Min Y, Byung-Ho CH,Jingxu L, Jae-Hyung J, HyeonJung L, Seoung-Ho L, et al. The effect of platelet-rich plasma on bone healing around implants placed in bone defects treated with Bio-Oss: A pilot study in the dogs tibia. Oral Surg Oral Med Oral Pathol Oral Radiol Endod 2007;103:3-12. 
115. Shi B, Zhou Y, Ning WY, Rong CX. Alveolar ridge preservation prior to implant placement with surgicalgrade calcium sulphate and platelet-rich plasma: A pilot study in a canine model. Int J Oral Maxillofac Implants 2007;22:656-65.

116. Tae-Ju OH, Billy E, Ho-Young B, Wang HL. Flapless implant surgery in the esthetic region: Advantages and precautions. Int J Periodontics Restorative Dent 2007; 27:27-33.

117. Cannizzaro G, Leone M, Marco E. Inmediate functional loading of implants placed with flapless surgery in the edentulous maxilla: 1-year follow-up of a single cohorty study. Int J Oral Maxillofac Implants 2007;22:87-95.

118. Jeong S, Choi B, Li J, Kim H, Ko C, Flapless implant surgery: An experimental study. Oral Surg Oral Med Oral Pathol Oral Radiol Endod 2007;104:24-8.

119. Flanagan D. Flapless dental implant placement. Int J Oral Maxillofac Implants 2007;33:75-83.

120. Zhang X, Chen S, Huang Y. Computer assisted design of orbital implants. Int J Oral Maxillofac Implants 2007; 22:132-7.

121. Tardieu P, Vrienlinck L, Escolano E, Henne MAT. Computer-assisted implant placement: scan template, simplant, surgiguide, and safe system. Int J Periodontics Restorative Dent 2007;27:141-9.

122. Rebaudi $A$. The ray setting procedure: $A$ new method for implant planning and inmediate prosthesis delivery. Int J Periodontics Restorative Dent 2007;27:267-75.

123. Choi N, Park Y, Lee H, Lee K. Treatment of class II protrusion with severe crowding using indirect miniscrew anchorage. Angle Orthodontist 2007;77: 1109-18.

124. Lin J, Liou E, Yeh C, Evans C. A comparative evaluation of current orthodontic miniscrew systems. World J Orthod 2007;8:136-44.

125. Sato R, Sato T, Takahashi I, Sugawara J, Takahashi N. Profiling of Clin Oral Impl Res 2007;18:21-6.

126. Song Y, Cha J, Hwang C. Mechanical characteristics of various orthodontics mini-screws in relation to artificial cortical bone thickness. Angle Orthod 2007;77:979-85.

127. Mauro M, Merli A, Esposito M. Palatal implant anchorage for orthodontic movement: Preliminary results with standard Bränemark implants. Int J Periodontics Restorative Dent 2007;27:43-9.

128. Morand M, Irinakis T. The challenge of implant therapy in the posterior maxilla: Providing a rationale for the use of short implants. J Oral Implantol 2007;8:257-66.

129. Cattaneo P, Dalstra M, Melsen B. An analysis of stress and strain around orthodontically loaded implants: An animal study. Int J Oral Maxillofac Implants 2007; 22: 213-25.

\section{CORRESPONDENCIA}

\section{Dr. Cosme Gay Escoda}

Centro Médico Teknon

Instituto de Investigación UB-IDIBELL.

C/Vilana 12

08022 Barcelona

E-mail: cgay@ub.edu

http://www.gayescoda.com 